\title{
Evaluation of wave impact loads on caisson breakwaters based on joint probability of impact maxima and rise times
}

\section{Giovanni Cuomo ${ }^{1 \& 2}$, Rodolfo Piscopia ${ }^{3}$ and William Allsop ${ }^{1 \& 4}$}

${ }^{1}$ HR Wallingford Howbery Park, Wallingford, OX10 8BA, UK

${ }^{2}$ HAREC s.r.l., Via Gregorio VII, 80, Rome, 00165, Italy

${ }^{3}$ Aquatecno s.r.l., Via Goito 39, 00185 Roma - Italy

${ }^{4}$ Department of Civil and Environmental Engineering, University of Southampton, UK

\section{Abstract}

When waves break against seawalls, vertical breakwaters, piers or jetties, they abruptly transfer their momentum into the structure. This energy transfer is always spectacular and perpetually unrepeatable but can also be very violent and affect the stability and the integrity of coastal structures. Over the last 15 years, increasing awareness of wave-impact induced structural failures of maritime structures has emphasised the need for a more complete approach to dynamic responses, including effects of impulsive loads. At the same time, movement of design standards toward probabilistic approaches requires new statistical tools able to account for uncertainties in the variability of wave loading processes. This paper presents a new approach to the definition of loads for use in performance design of vertical coastal structures subject to breaking wave impacts. Based on conservation of momentum and joint probability of non-dimensional wave impact maxima and rise times from large-scale test measurements, a new set of equations have been derived to characterise design impact loads at different non-exceedance probability levels and guidance is given for the estimation of the static-equivalent design loads to be used in early-stage feasibility studies. Predictions of static equivalent design loads and corresponding safety factor against sliding using the proposed methodology are found to be in very good agreement with both predictions by most established deterministic methods and field observations reported in literature.

This is the author's version of a work that was accepted for publication in Coastal Engineering. Changes resulting from the publishing process, such as peer review, editing, corrections, structural formatting, and other quality control mechanisms may not be reflected in this document. Change may have been made to this work since it was submitted for publication. A definitive version was subsequently published in Coastal Engineering, Volume 58, Issue 1, January 2011. DOI:10.1016/j.coastaleng.2010.08.003 


\section{Keywords}

Wave loads; Wave impacts; Joint probability; Caisson breakwaters; Coastal structures; Design load, Performance design, Probabilistic design methods

\section{Introduction}

Despite their magnitude, wave impacts have only rarely been included in structural analysis of coastal structures, sometimes leading designers to ignore short-duration wave loads, perhaps contributing to failure of a range of breakwaters, seawalls and suspended decks. Over the last 15 years, improved awareness of wave impact induced failures of coastal structures (Franco 1994; Oumeraci 1994; Goda 2000; Allsop, 2000), has focused attention on the need to include dynamic responses to wave impact loads in designing of maritime structures. Small and large scale physical model tests (see e.g. Allsop et al. 1996, Bullock et al. 2004, Cuomo et al. 2010) have demonstrated that wave impact loads on walls can be much higher than pulsating loads predicted by standard methods and highlighted the need for further investigations of the physics that stands behind wave breaking onto coastal structures.

Extracts from a typical load time-history recorded during physical model tests on vertical walls under wave breaking attack are shown in Figure 1. Sharp impacts are evident, with significantly different maxima and rise times, followed by slowly-varying pulsating loads. Various recent experiments have recorded and analysed violent wave impacts on vertical structures. These new data are however only useful for design if methods become available to predict not only wave impact loads and their variability but also the dynamic responses of maritime structures to short-duration loads.
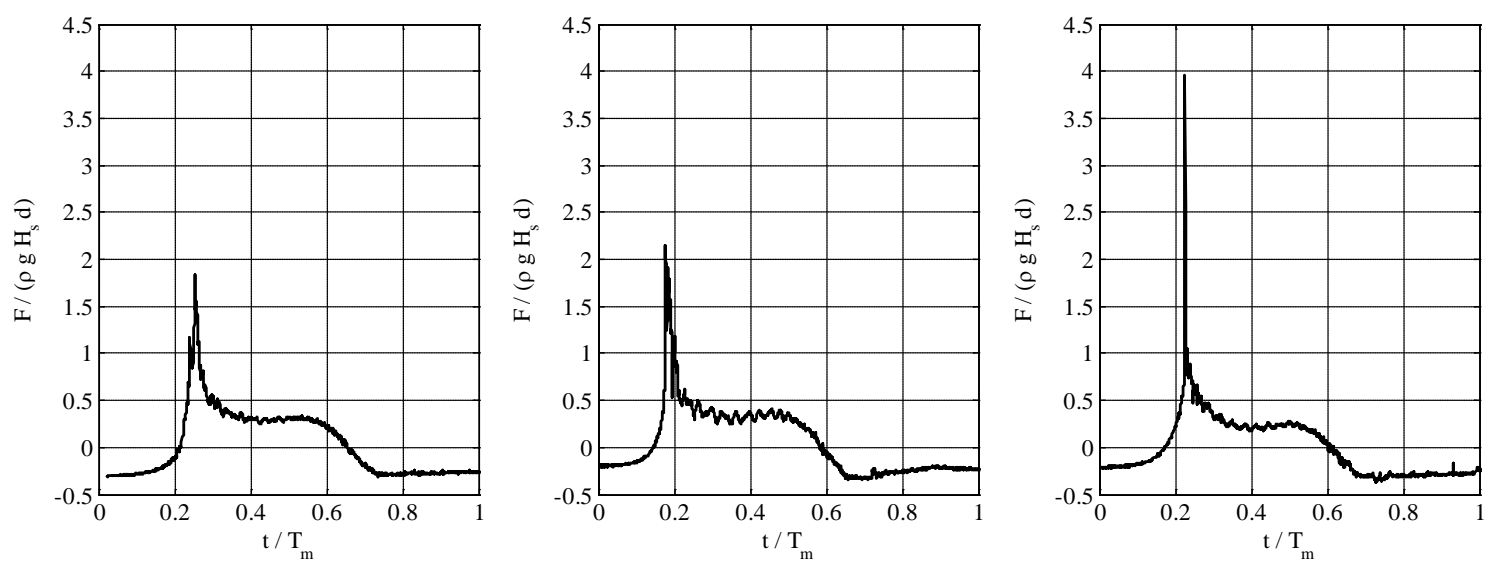

Figure 1 Wave-impacts force time-histories from large-scale physical model tests. Nominal (model) condition equal to: $\mathrm{H}_{\mathrm{s}} \mathrm{O}=0.48 \mathrm{~m}, \mathrm{~T}_{\mathrm{m}}=2.56 \mathrm{~s}, \mathrm{~d}=0.83 \mathrm{~m}, \mathrm{R}_{\mathrm{c}}=1.16 \mathrm{~m}$

For seawalls or crown walls, dynamic analysis has been rare (Allsop, 2000) and wave impact loads are often ignored in design despite their magnitude. For caisson breakwaters, simplified models (Goda 1994, Omeraci and Korthenhaus, 1994) and more sophisticated ones (Takahashi et al., 1994, Oumeraci et al. 2001) have been proposed in the past to describe the dynamics of caisson breakwaters. A complete methodology for the design of caisson breakwaters subject to impulsive wave-loading is nevertheless still missing and international standards suggest avoiding such structures at sites where significant wave breaking might be expected. Unfortunately, this is often the case when (as may easily occur along the North European coasts), 
a large tidal excursion and severe environmental conditions coincide to expose vertical breakwaters or seawalls to impulsive wave loads.

Improvements in predictions of effective loads on vertical structures exposed to wave breaking using dynamic analysis require development of more refined wave load models based on new measurements and experiments. Takahashi et al. (1994) extended methods by Goda (1974) to account for impulsive wave conditions by amplification factors depending on the geometry of the structure and its foreshore. The method has been included in Goda (2000) and is recommended by international standards worldwide. Nevertheless, none of the above methods gives guidance on the duration of the loading nor accounts explicitly for the dynamics response of the caisson itself.

More recently, within the framework of the PROVERBS (PRObabilistic design tools for VERtical BreakwaterS) research, Oumeraci et al. (2001) gave guidelines for assessment of wave forces on seawalls under breaking and non-breaking conditions. The PROVERBS results represents the most recent and significant European effort towards the understanding and assessment of wave loads, and includes guidance to estimate impact magnitudes and durations, and their effects on caisson breakwaters. The application of the PROVERBS methodology is nevertheless complex and may still lead to significant scatter in predictions of wave loads even under relatively similar design conditions (Cuomo et al., 2007) with predicted design loads being often significantly different from estimates by the most generally accepted and established design methods.

Here, we provide an improved wave-impulse model based on the joint probability distribution of nondimensional impact force maximum and rise time. The statistical model is based on dataset from large-scale test measurements carried out at the CIEM-LIM wave flume of University "Politècnica de Catalunya" (UPC) under the Big-VOWS project.

Using this joint probability model, correlation curves between impact maxima and rise times are derived at a number of fixed probability levels, making possible to generate pulse time-histories with specific nonexceedance probability level of impact maxima and rise time, that are suitable for use in dynamic analysis of maritime structures exposed to impulsive breaking wave loads.

Based on the analogy of caisson breakwaters with a Single Degree of Freedom (SDOF) system, guidance is given for the estimation of the dynamic response of the structure and its use in assessing the staticequivalent design load at different probability levels.

The present methodology moves from work by Cuomo (2007) and Piscopia et al. (2007) and allows to account efficiently for both the stochastic nature of impact loads and the dynamic response of caisson breakwaters. Prediction are shown to be in general agreement with both field measurements and most established deterministic prediction models.

\section{Previous work}

Many researchers have focused on measuring and analysing wave impact loads on maritime structures, the physics that stands behind the loading process is nevertheless not yet completely understood, partially due to the difficulties in measuring short-duration wave impact pressures and in dealing with the large volume of data to be stored and analysed. In this work, we briefly summarize the main results presented in literature, for a more comprehensive review, reference might be made to Peregrine, (2003) or Cuomo et al. (2010) and references therein. 
Work by Bagnold (1939) laid foundations for much subsequent research. The author distinguished between wave pressures exerted by "not breaking" waves (which later will be referred to as "pulsating" or "quasi static") and breaking waves ("impacts" or "impulsive"). Bagnold first noticed the importance of entrained air, and observed that impact pressures were greatest when air trapped by the wave as it hits the wall was least, but not zero.

Mitsuyasu (1966) measured impact pressures induced by regular waves breaking onto a vertical wall, placed at the top of a 1:15 beach slope, recording pressures up to $320 \mathrm{~g} / \mathrm{cm}^{2}$ with duration of about $0.0035 \mathrm{~s}$.

Experimental work by Richert (1968) and Kamel (1970) confirmed the relative importance of the air cushion to the magnitude of initial peak pressure as well as on the duration of the succeeding damped oscillations. The thicker the cushion of enclosed air, the lower the peak pressure and longer the oscillation period.

Based on observations during wave flume tests and considerations on the conservation of wave momentum, Weggel and Maxwell (1970) suggested a tentative relationship between maximum impact pressure $P_{\max }[\mathrm{Pa}]$ and the time needed to transfer wave kinetic energy to the wall $t[\mathrm{~s}]$ in the general form:

$$
P_{\max }=a \cdot t^{b}
$$

where $a=232$ and $b=-1$ are non-dimensional empirical coefficients. It is important to note that Equation 1 is not dimensionally consistent, suggesting that a more complete version could be usefully derived.

Kirkgöz performed an extensive series of experiments on breaking wave loads on vertical walls using artificially derived single waves. Kirkgöz $(1982,1983)$ pointed out the relative importance of deep-water wave steepness and beach slope on both the maximum peak pressure and its position up the wall. Successive physical model tests (Kirkgöz 1991, 1992 and 1995) confirmed that the variation of the rise time $\left(t_{r}\right)$ taken to rise pressure from zero to its maximum value $\left(P_{\max }\right)$ within an impulsive loading event (Figure 2 ) obey Equation 1 but with values of coefficient $a$ and $b$ respectively equal to 250 and -0.9 . 


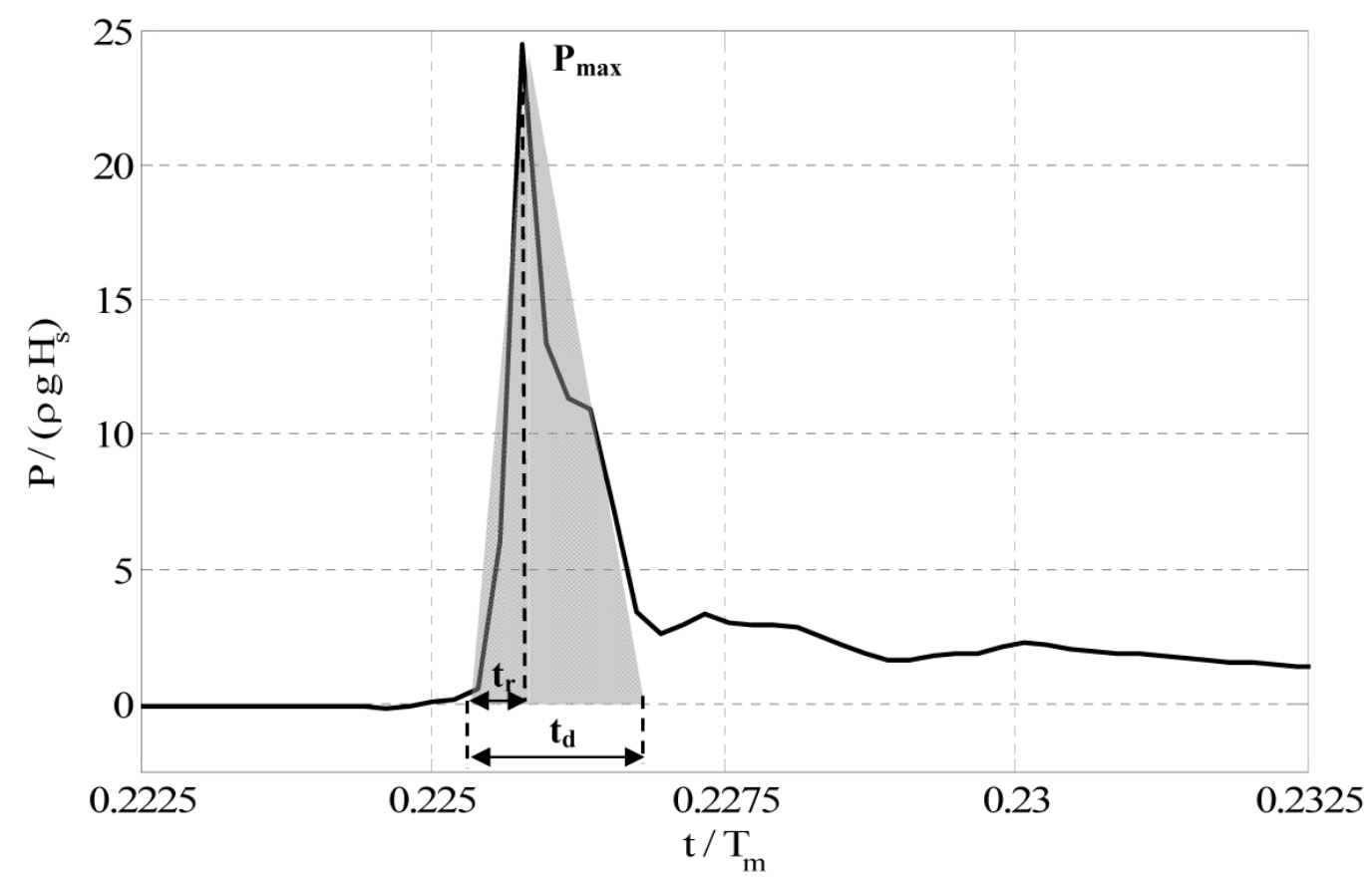

Figure $2 \quad$ Idealized time-history superimposed to an example impact pressure record from physical model tests. In the plot: $\mathrm{P}_{\max }$ is the peak pressure, $\mathrm{t}_{\mathrm{r}}$ is the rise time, $\mathrm{t}_{\mathrm{d}}$ is the total impact duration time; shaded area represents total impulse

Hattori and Arami (1992), Hattori (1994) and Hattori et al. (1994) used regular waves for their experimental work on wave impacts on vertical walls. The authors confirmed the predominant role of the air trapped between the wall and the wave in the physics of high impact pressures, with the most severe impact occurring when the breaker strikes the wall with an almost vertical face, trapping a relatively small amount of air. The larger the amount of entrapped air, the lower the peak pressure maxima and the longer the rising time of the impact. Assuming an adiabatic compression of the trapped air pocket, the authors proposed a predictive model for breakers plunging against vertical walls that was found to explain fairly well both the maximum impact pressure and the frequency of the damped pressure oscillation. The functional relation between impact pressure maxima and rise times was found to follow Equation 1 with values for coefficient $a$ and $b$ respectively equal to 400 and -0.75 .

Within the framework of the PROVERBS research project (Oumeraci et al, 2001) a new procedure was developed for the assessment of wave impact loads on sea walls. The new methodology was the first to quantitatively account for uncertainties and variability in the loading process and represents a step forward in the development of a more rational and reliable design tool. Moving from the identification of the main structural geometrical aspects and wave parameters, the method proceeds through 12 steps to the evaluation of the wave forces (shoreward, up-lift and seaward) expected to act on the structure, together with the corresponding impact rise times and pressure distribution up the wall. The new design methods are described in details in Oumeraci et al. (2001), Klammer et al. (1996) and Allsop et al. (1999). According to the guidelines delivered within the project, the maximum landward impact force is given by:

$$
F_{i m p}=F_{i m p}^{*} \cdot \rho g H_{b}^{2}
$$


where $H_{b}$ is the wave height at breaking (Oumeraci et al, 2001) and the relative maximum wave force $\mathrm{F}_{\mathrm{imp}}{ }^{*}$ is distributed according to the Generalised Extreme Value (GEV).

On occasion, two force peaks were observed, followed by lower force oscillations, perhaps caused by cyclic compression and expansion of the air pocket trapped at impact. The period of the force oscillation was assumed (Oumeraci et al. 1992) to be a linear function of the equivalent diameter of the air pocket. For usual dimension of trapped air pocket, the period of oscillation of the loading was found to lie in the range of the natural period of prototype caisson breakwaters, and therefore to represent near-to-resonance excitation.

Coefficients $a$ and $b$ in Equation 1 given in literature also include those summarised in Table 1 highlighting large variability among estimates given by different authors. This is only partially due to the difficulties of recording comparable impact pressures from different tests. Walkden and Bruce (1999) suggest a number of other factors:

Table 1 Coefficients $a$ and $b$ in Equation 1 from previous experiments at small and large scale

\begin{tabular}{llrc}
\hline \multicolumn{1}{c}{ Researcher } & Scale & \multicolumn{1}{c}{$\boldsymbol{a}$} & \multicolumn{1}{c}{$\boldsymbol{b}$} \\
Weggel \& Maxwell, 1970 & Small & 232 & -1.00 \\
Blackmore \& Hewson, 1984 & Full & 3100 & -1.00 \\
Kirkgoz, 1990 & Small & 250 & -0.90 \\
Witte, 1990 & Small & 261 & -0.65 \\
Hattori et al., 1994 & Small & 400 & -0.75 \\
Bullock et al., 2001 & Full & 31000 & -1.00 \\
\hline
\end{tabular}

- bathymetry, permeability and roughness of the foreshore in front of the structure;

- wave height, period and direction;

- measurement apparatus (transducer size, location, sample rate and frequency response);

- model scale;

- structural configuration tested;

- model dynamic response;

a aeration.

Among the others, aeration is generally acknowledged to be one of the most important cause of variability in wave impact maxima, either in the form of trapped pockets, expelled air or trapped bubbles.

Bagnold (1939) identified the thickness of the air layer trapped at impact as the main cause of scatter in wave pressure maxima, while the first classification of wave shocks is attributed to Lundgren (1969), who distinguished:

ventilated shock: when the wave front approaches the face of the wall so that no air is trapped;

- compression shock: when the wave front approaching the wall is concave and the wave crest curls trapping an air pocket between the wave front and the structure;

- hammer shock: when the forward pointing crest of a plunging breaker hits the wall.

Lundgren assumed the maximum wave impact pressure to be given by:

$$
P_{\max }=\frac{\rho \cdot H_{b} \cdot U}{2 t_{r}}
$$


where $t_{r}=A_{V} /\left(U H_{b}\right)$ is the impact rise-time, $H_{b}$ and $U$ are respectively the breaker height and velocity, and $A_{V}$ the volume of air expelled at impact. Small changes in $A_{V}$ may therefore result in large variation of $P_{\max }$.

Other than variations in geometry (foreshore, wave height and steepness), changes in $A_{V}$ might be due to different air content in still and sea water or to scale effects on air compressibility. According to Lundgren (and confirmed by latter researchers), wave impulse can be scaled to prototype by Froude's law. Scaling maximum pressures by Froude's law will therefore be correct for well-ventilated shocks, but might be overconservative when air is trapped during impact, since different levels of aeration between model and prototype might affect pressure maxima and rise-times beyond Froude scaling factors. For compression shocks, Lundgren suggested adopting a "model law" (after Mitsuyatsu, 1966) for scaling of maximum pressures to prototype, but warned that using Froude law for scaling hammer shocks might lead to overestimation of impact maxima. The problem of scaling from model to prototype has been discussed more fully by Cuomo et al (2010).

Walkden et al. (1996) compared impact forces and total impulse durations ( $t_{d}$ in Figure 2 ) on caisson breakwaters at small and large scale. For small-scale test best-fit parameters $a$ and $b$ were found to be respectively $a=21.4$ and $b=-0.92$. The best-fit of the large-scale data was obtained for parameters $a$ and $b$ respectively equal to $a=1900$ and $b=-1.00$.

Similarly to Equation 1, a relation between the impact force $F_{\max }$ and rise time $t_{r}$ can be written as follows:

$$
F_{\text {max }}=a \cdot t_{r}^{b}
$$

where $F_{\max }[N]$ is the maximum force and $t_{r}[s]$ its corresponding rise-time; $a$ and $b$ are again empirical coefficients. Hereinafter, the following dimensionless form (McConnell and Kortenhaus, 1996) is used to modify Equation 4:

$$
\frac{F_{\max }}{F_{q s+, 1 / 250}}=a \cdot\left(\frac{t_{r}}{T_{m}}\right)^{b}
$$

where $T_{m}$ is mean wave period and $F_{q s^{+}, 1 / 250}$ is the average of the four higher values of quasi-static force within a $N_{z}=1000$ waves test. Equation 5 has been found to represent well the variability of wave impacts and to extend the generality of the analysis since reliable methods exist for the evaluation of quasi-static force at $1 / 250$ level $\left(F_{q s+1 / 250}\right)$ by Goda (2000), Oumeraci et al. (2001) and Cuomo et al (2010).

\section{Description of the experimental data}

Large-scale experiments were performed at the CIEM / LIM wave flume at Universitat Politècnica de Catalunya, Barcelona (UPC), under the Big-VOWS project. Experimental setup and the main findings in terms of wave overtopping and wave induced loads are described in detail in Pearson et al. (2002) and Cuomo et al. (2010). In the following, a summary of tested conditions is given together with a short description of the experimental data.

Tests were performed using five different water depths $d$, ranging between $0.53 \mathrm{~m}$ and $1.28 \mathrm{~m}$ and values of the freeboard $\left(R_{c}\right)$ ranging between $0.71 \mathrm{~m}$ and $1.46 \mathrm{~m}$. The test matrix of 39 different wave conditions is summarized in Table 2 in terms of significant spectral wave height $\left(H_{m 0}\right)$ and mean period $\left(T_{m}\right)$. 
Table 2. Summary of test conditions

\begin{tabular}{cccc}
\hline Test & Configuration & $\begin{array}{c}\text { Nominal wave period } \\
\mathbf{T}_{\mathbf{m}}[\mathbf{s}]\end{array}$ & $\begin{array}{c}\text { Nominal wave height } \\
\mathbf{H}_{\text {is }}[\mathbf{m}]\end{array}$ \\
& & 2.56 & $0.48,0.45,0.37$ \\
1A \& 1B & $\mathrm{Rc}=1.16 \mathrm{~m} / 1.40 \mathrm{~m}$ & 3.12 & $0.60,0.56,0.39$ \\
& $\mathrm{~d}=0.83 \mathrm{~m}$ & 3.29 & 0.67 \\
& & 3.64 & 0.60 \\
& & 1.98 & 0.25 \\
1C & $\mathrm{Rc}=1.46 \mathrm{~m}$ & 1.98 & $0.25,0.22$ \\
& $\mathrm{~d}=0.53 \mathrm{~m}$ & 2.56 & $0.48,0.45,0.37,0.23$ \\
& & 3.12 & $0.63,0.60,0.56,0.39$ \\
& & 3.29 & 0.67 \\
1D \& 1E & $\mathrm{Rc}=0.71 \mathrm{~m} / 0.95 \mathrm{~m}$ & 3.64 & 0.60 \\
& $\mathrm{~d}=1.28 \mathrm{~m}$ & 1.97 & $0.26,0.23$ \\
& & 2.54 & $0.44,0.35,0.23$ \\
& & 3.12 & $0.58,0.50,0.34$ \\
1F \& 1l & $\mathrm{Rc}=1.38 \mathrm{~m} / 1.42 \mathrm{~m}$ & 3.65 & 0.55 \\
& $\mathrm{~d}=0.82 \mathrm{~m}$ & 2.60 & 0.46 \\
& & 3.15 & $0.59,0.51$ \\
& & 3.40 & 0.59 \\
1G \& 1H & $\mathrm{Rc}=0.98 \mathrm{~m} / 1.02 \mathrm{~m}$ & 3.80 & 0.51 \\
& $\mathrm{~d}=1.22 \mathrm{~m}$ & 3.15 & 0.59 \\
& & 3.40 & 0.59 \\
& & 3.80 & 0.51 \\
\hline
\end{tabular}

Pressures up the wall were measured by a vertical array of 8 pressure transducers, spaced vertically by $20 \mathrm{~cm}$, logging at a frequency of $2000 \mathrm{~Hz}$. This was assumed to give a sufficiently sharp description of wave impact loads (Klammer et al., 1994).

The total horizontal force $\left(F_{h}\right)$ and overturning moment $\left(M_{z}\right)$ on the seaward face of the wall were computed respectively as:

$$
\begin{aligned}
& F_{h}=\sum_{k} P^{k} \cdot \Delta z \\
& M_{z}=\sum_{k} P^{k} \cdot \Delta z \cdot z^{k}
\end{aligned}
$$

where $P^{k}$ is the pressure recorded by the $k^{\text {th }}$ pressure transducer and $\Delta z=0.20 \mathrm{~m}$ is the distance up the wall between two successive transducers and $z^{k}$ is the absolute position of the $k^{\text {th }}$ transducer up the wall, including the top and the bottom sensors of the array.

Visualization of pressure distribution as measured from sensors up the wall confirmed the array to cover the whole area of application of wave loads and Equations 6 and 7 to provide an efficient evaluation of global wave forces acting on the wall and that overtopping did not significantly affect the distribution of wave pressures up the wall all over the range of freeboards $\left(R_{c}\right)$ tested. Example wave impact force time-histories 
in Figure 1 were computed from pressure time-histories recorded during test run under nominal (model) condition equal to: $H_{m 0}=0.48 \mathrm{~m}, T_{m}=2.56 \mathrm{~s}, d=0.83 \mathrm{~m}, R_{c}=1.16 \mathrm{~m}$.

Values of wave impact force and rise-time as recorded at UPC have been analyzed to assess the variability of wave impacts within each test of $N_{z}=1000$ waves. For each wave impact on wall, the following parameters were extracted from pressure signals recorded up the wall:

- time $t_{0}$ corresponding to the beginning of the event;

- impact maximum force $F_{\text {imp }}$;

- corresponding rise time $t_{r}=t\left(F_{\text {imp }}\right)-t_{0}$;

- maximum quasi-static load $F_{q s+}$.

Whilst the value of $F_{\text {imp }}$ recorded during an impact is likely to be influenced by the spatial and temporal resolution of the measurements, the value of $t_{r}$ is most likely to be influenced by the threshold used to define the beginning of the event. Based on work by McConnell and Kortenhaus (1996), to facilitate the comparison of data with different levels of noise, an event was assumed to start each time $F_{h}$ up-crossed the background noise-threshold level: $F_{\min }=0.2 \cdot \rho g \cdot d \cdot H_{m 0}$, where $H_{m 0}$ is the incident spectral significant wave height and $\rho$ and $g$ are respectively the water density and the gravitational acceleration.

The distinction between impulsive $\left(F_{\text {imp }}\right)$ and quasi-static forces $\left(F_{q s^{+}}\right)$was based on the relative duration of the loading. In particular, "impacts" or "short-duration" forces are those that act on the structure for durations shorter or comparable with the natural period of oscillation the structure $\left(T_{0}\right)$. Conversely, "quasi-static" (also called slowly-varying or pulsating) forces are those that act on the structure for longer than twice its natural period of vibration.

For each run, the horizontal quasi static shoreward force at significance level 1/250 $\left(F_{\text {qS }^{+}, 1 / 250}\right)$ was also extracted and used to normalise impact maxima $F_{i m p}^{*}=F_{i m p} / F_{q s+, 1 / 250}$. The overall sample size was equal to 12998 pairs of non-dimensional impact-force $F_{i m p}^{*}$ and rise-time $t_{r}^{*}=t_{r} / T_{m}$.

\section{Bivariate inference on impact maxima and rise times}

Since Bagnold's pioneering work, impact pressures were found to largely vary even for fixed nominal conditions whereas the pressure impulse I, defined as:

$$
I=\int P \mathrm{dt}
$$

that is, the integral of pressure $P$ over time $t$, was far more repeatable. Nevertheless, using impulses in dynamic analysis is only meaningful in the range of impact duration in which the dynamic amplification is not affected by the pulse shape (Chopra, 2001). This is not the case for wave-induced loads on caisson breakwaters (Cuomo, 2007), and therefore evaluating the dynamic amplification to use in design requires the specific knowledge of the dependence between impact maxima and rise times.

Being impulses finite quantities, shorter rise time will correspond to more intense impact force and vice versa. The first stochastic description of the correlation between impact forces and their rise-time can be 
found (Oumeraci et al., 2001) who suggest evaluating impact rise time using the following function of the relative maximum wave force $F_{i m p}^{*}$ (as defined in Equation 2):

$$
t_{r}=k_{m} \cdot \frac{\sqrt{d_{e f f} / g}}{F_{i m p}^{*}}
$$

where $d_{\text {eff }}$ is the effective water depth at the structure as a function of the geometrical characteristics of the foreshore (Oumeraci et al. 2001), and $k_{m}$ the mass parameter (Klammer et al. 1996), which can be assumed to follow a Log-Normal distribution with mean equal to 0.086 and variance equal to 0.084 . The following expression is also suggested for impact duration:

$$
t_{d}=-\frac{c_{d}}{\ln t_{r}}
$$

empirical parameter $c_{d}$ being normally distributed with mean equal to 2.17 and variance equal to 1.08 .

Differently, in the present work, the reciprocal dependency of impact magnitude and its rise time is described using a more sophisticated, multi-parametric, bivariate, statistical model, i.e. a joint-probability distribution able to describe both coupled and conditional occurrences of impact maximum and rise time.

Here we implement the method to set up bivariate probability distributions with arbitrary marginals (i.e. the probability distribution of a single variable) using copulas. This allow to break apart the dependence structure and the marginal behaviour of a joint distribution function or, in other words, the use of copulas functions enable studying marginal behaviours and their correlation in separate, consecutive steps, and to handle all this information in a single analytical function. From this point of view, copulas are powerful tools that allow to approximate the exact joint-probability distribution law for which an explicit algebraic expression is not available.

Copulas have been studied in the probability literature for about 50 years since Fréchet $(1951,1956,1958)$, and therefore many properties of copulas are now widely known (Genest and Mc Kay, 1986; Joe, 1997; Nelsen, 2006). The application of copulas to ocean and coastal engineering problems nevertheless has a relatively short history, with most reference dating back no more than two decade. Athanassoulis et al. (1994) described wave climate, Piscopia et al. (2002) pointed at the dependence between the shape parameters of wave spectra and the corresponding significant wave height and peak period whereas de Waal and van Gelder (2005) modelled the extreme wave heights and periods relation. Bearing in mind that the use of copulas in the coastal engineering community has so far only been rare, in the following we provide a short description of the theoretical basis that stands behind the application of this statistical tool.

The main asset of copulas results from the theorem by Sklar (1959) which, roughly speaking, points out that if two random variables $x$ and $y$ exist with univariate cumulative distributions $P(x)$ and $G(y)$ (marginals), there exists a function called copula $(C)$ that joins the marginal distributions to give a bivariate cumulative distribution $F(x, y)=C(P(x), G(y)$ ). It can also be proven (Kimeldorf and Sampson, 1975a, 1975b) that the general problem of defining all the possible multivariate probability models whit arbitrary marginals $P_{\mathrm{i}}\left(x_{\mathrm{i}}\right)$ can be reduced to the study of the correlation structure of multivariate probability models having uniform marginals.

Straightforward practical consequences of these properties are that: a) different copulas can be used with any kind of marginal distribution and $b$ ) the identifications of the univariate models that best-fit the data and the copula function that performs best can be carried out independently. In other words, the parameter set 
on which the joint-probability distribution depends can be decomposed into 3 independent sub-sets: 2 arrays controlling the marginal distributions and 1 group conditioning the data correlation.

Also, if the marginal distribution $P(x)$ and $G(y)$ are continuous functions, then the conditional distribution function $F_{P}(y \mid x)$ can be defined as:

$$
F_{P}(y \mid x=\hat{x})=\left.\frac{\partial}{\partial x} C(P(x), G(y))\right|_{x=\hat{x}}
$$

In what that follows we will give details of techniques used to evaluate both the marginal probability distributions and the association parameter on which the bivariate distribution depends. In particular we will first analyse the families of univariate probability distribution functions that are able to model independently impact forces maxima and their rise times; we will then describe in detail the technique used to estimate the parameters (position, scale and shape) of the marginal probability distributions. Finally, we will describe the copula model used to describe the correlation of the data and the technique used to estimate its association parameter.

\subsection{Marginal distributions of wave impact and rise times}

As anticipated in Section 3, wave impact maxima were normalised using the quasi-static shoreward horizontal force at significant level $1 / 250\left(\mathrm{~F}_{\mathrm{qs}+1 / 250}\right)$. Sample frequencies for data extracted from each test part are superimposed in Figure 3, showing that the normalised data extracted from each test part follow the same probability distribution and suggesting analysing the collected data as a whole dataset. The best-fit probabilistic model for the dimensionless impact forces $F_{i m p}^{*}$ was identified by routinely testing the following distribution functions (Evans et al., 2000) using Matlab ${ }^{\circledR}$ libraries: Beta, $\chi^{2}$, Exponential, Gamma, Generalised Extreme Value (GEV), Generalized Gamma, Generalized Pareto (GP), Gumbel, Inverse Gaussian, Lognormal, Normal, Rayleigh, Truncated Rayleigh, Student's $\tau$, Weibull, Truncated Weibull.

The task was performed fitting each and every of the aforementioned distribution laws to the dataset and selecting the one with the least square error, defined as the difference between the data frequency and its corresponding theoretical probability for each given value of $F_{i m p}^{*}$. Confirming what suggested from previous work (Oumeraci et al., 2001, Cuomo 2005) the GEV distribution was found to best-fit to experimental data. 


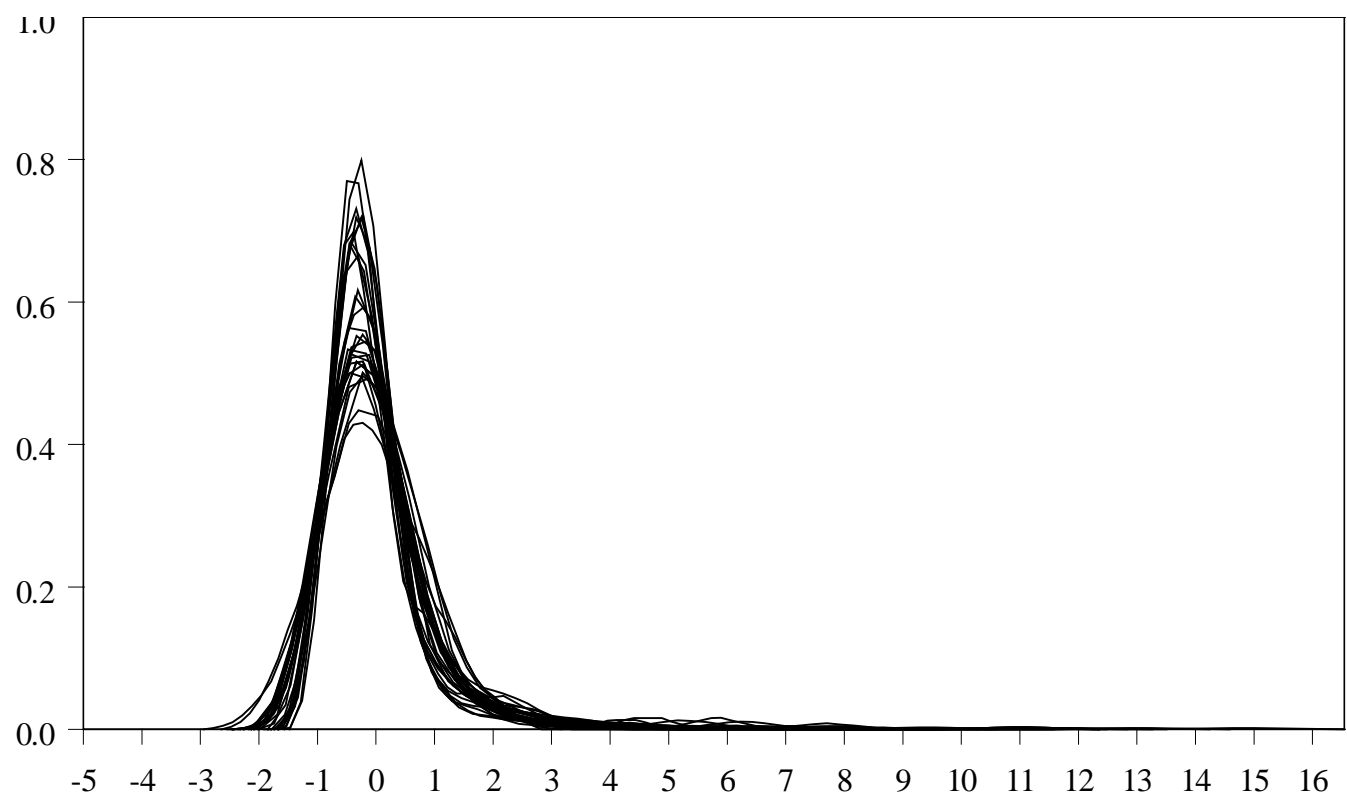

\section{Figure $3 \quad$ Normalized-impact frequencies distribution for each experimental test.}

Accordingly, the following expression is therefore adopted to model the cumulate probability distribution of dimensionless impact force maxima (Jenkinson, 1955; Johnson et al., 1994; Coles, 2001):

$$
\begin{aligned}
& P\left(F_{i m p}^{*}\right)=\exp \left(-\left(1-k \cdot \frac{\left(F_{i m p}^{*}-A\right)}{B}\right)^{1 / k}\right) \text { for } k \neq 0 \\
& P\left(F_{i m p}^{*}\right)=\exp \left(-\exp \left(-\frac{\left(F_{i m p}^{*}-A\right)}{B}\right)\right) \text { for } k=0
\end{aligned}
$$

where $A, B$ and $k$ are respectively the position, scale and shape parameters, whose values are computed as stated in section 4.2

The following expression is accordingly used to model the probability density distribution for $F_{\text {imp }}^{*}$ :

$$
\begin{aligned}
& p\left(F_{i m p}^{*}\right)=\frac{1}{B}\left(1-k \frac{\left(F_{i m p}^{*}-A\right)}{B}\right)^{(1-k) / k} \exp -\left(1-k \cdot \frac{\left(F_{i m p}^{*}-A\right)}{B}\right)^{1 / k} \text { for } k \neq 0 \\
& p\left(F_{i m p}^{*}\right)=\frac{1}{B} \exp \left(-\frac{\left(F_{i m p}^{*}-A\right)}{B}\right) \exp -\left(\exp \left(-\frac{\left(F_{i m p}^{*}-A\right)}{B}\right)\right) \text { for } k=0
\end{aligned}
$$


A series of adaptation tests of the aforementioned distribution laws was also performed for the nondimensional rise times $t_{r}^{*}$. The Generalized Pareto (Pickands, 1975; Johnson et al., 1994; Coles, 2001) was identified as the best-fitting distribution, leading to the following expression for the probability density distribution of $t_{r}^{*}$ :

$$
\begin{aligned}
& G\left(t_{r}^{*}\right)=1-\left(1+\kappa \frac{\left(t_{r}^{*}-\mu\right)}{\eta}\right)^{-1 / \kappa} \text { for } \kappa \neq 0 \\
& G\left(t_{r}^{*}\right)=1-\exp \left(-\frac{\left(t_{r}^{*}-\mu\right)}{\eta}\right) \text { for } \kappa=0
\end{aligned}
$$

where again $\mu, \eta$ and $\kappa$ are respectively the position, scale and shape parameters, whose values are computed as stated in section 4.2; the following expression is accordingly used to model the probability density distribution of $t_{r}^{*}$ :

$$
\begin{aligned}
& g\left(t_{r}^{*}\right)=\frac{1}{\eta}\left(1+\kappa \frac{\left(t_{r}^{*}-\mu\right)}{\eta}\right)^{-(\kappa+1) / \kappa} \text { for } \kappa \neq 0 \\
& g\left(t_{r}^{*}\right)=\frac{1}{\eta} \exp \left(-\frac{\left(t_{r}^{*}-\mu\right)}{\eta}\right) \text { for } \kappa=0
\end{aligned}
$$

\subsection{Estimation of marginals parameter set}

Having settled the statistical univariate models for both the dimensionless impact force maxima and their rise times makes it possible to focus on the best performing method to estimate their parameter values. Here we have compared results obtained by using the least square error method (LSEM), the maximum log-likelihood method (MLLM) and the method of $L$-moments.

The least square error and maximum log-likelihood methods involve, respectively, the minimization and the maximization of the following expressions (see for example Lawless, 1980):

$$
\begin{aligned}
& \sum_{i=1}^{N}\left(P_{i, N}-P\left(x_{i}, \lambda\right)\right)^{2} \\
& \sum_{i=1}^{N} \log \left\{p\left(x_{i}, \lambda\right)\right\}
\end{aligned}
$$


where $\lambda$ is the unknown parameter vector ( $\lambda=[A, B, k]$ for GEV and $\lambda=[\mu, \eta, \kappa]$ for GP) and $P_{i, N}$ is the nonexceedance cumulate frequency of the sample $x_{i}$, given by:

$$
P_{i, N}=\frac{i}{N+1}
$$

where $i$ is the sample ranking index (for a descending ordered series) and $N$ is the sample size. The values of the parameter vectors giving the minimum value of Equation 20 or the maximum of Equation 21 were obtained using the numerical algorithm named "Complex" method (Box, 1965; Gill and Murray, 1975), a multi-parameter, nonlinear, constrained, optimization algorithm by direct-search (details on implementation are given in the Appendix). The adopted numerical-method search the equation solution in a sub-region of the parameter-space (i.e. all possible values of $\lambda$ terms, eventually limited by specific constrain on the allowable values of each $\lambda$ term) until the relative error is less than $10^{-6}$.

The method of $L$-moments (Greenwood et al., 1979) estimates the parameter vector by means of arithmetic expressions, which are functions of the probability-weighted moments. For the generalized extreme value distribution, the parameter expressions are as follows (Hosking et al., 1985; Hosking, 1990)

$$
\begin{aligned}
& A=\beta_{0}+B \frac{[\Gamma(1+k)-1]}{k} \\
& B=\frac{\left(2 \beta_{1}-\beta_{0}\right) k}{\Gamma(1+k)\left(1-2^{-k}\right)} \\
& \frac{\left(3 \beta_{2}-\beta_{0}\right)}{\left(2 \beta_{1}-\beta_{0}\right)}=\frac{\left(1-3^{-k}\right)}{\left(1-2^{-k}\right)}
\end{aligned}
$$

where the probability weighted moments (PWM) $\beta_{r}, r=0,1,2$, are given by the following expression:

$$
\beta_{r}=\int_{0}^{1} x(P) P^{r} d P
$$

The evaluation of PWM was carried out using the following estimator:

$$
\hat{\beta}_{r}=\frac{1}{N} \sum_{i=1}^{N} P_{i, N}^{r} X_{i}
$$

Equations 23, 24 and 25 are computed successively starting from Equation 25, which is solved iteratively by using the Newton-Rapson method with starting point given by:

$$
k_{0}=7.859\left(\frac{2 \beta_{1}-\beta_{0}}{3 \beta_{2}-\beta_{0}}-\frac{\log 2}{\log 3}\right)+2.9554\left(\frac{2 \beta_{1}-\beta_{0}}{3 \beta_{2}-\beta_{0}}-\frac{\log 2}{\log 3}\right)^{2}
$$

which is a satisfying approximation of Equation 25 proposed by Hoskins et al. (1985).

For the generalized Pareto distribution, the parameter expressions are as follows (Pandely et al., 2001)

$$
\mu=\beta_{0}-(2-k)\left(2 \beta_{1}-\beta_{0}\right)
$$




$$
\begin{aligned}
& \eta=(1-k)(2-k)\left(2 \beta_{1}-\beta_{0}\right) \\
& k=\frac{3\left(6 \beta_{2}-6 \beta_{1}+\beta_{0}\right)-\left(2 \beta_{1}-\beta_{0}\right)}{\left(6 \beta_{2}-6 \beta_{1}+\beta_{0}\right)+\left(2 \beta_{1}-\beta_{0}\right)}
\end{aligned}
$$



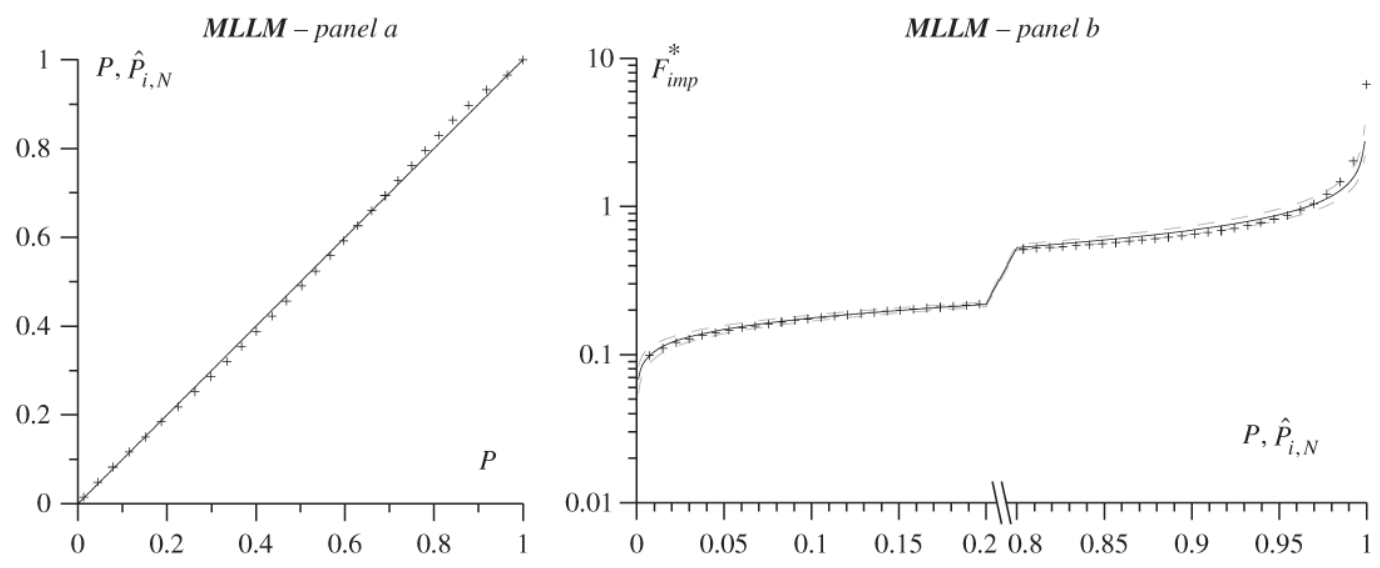

$L$-moments - panel a
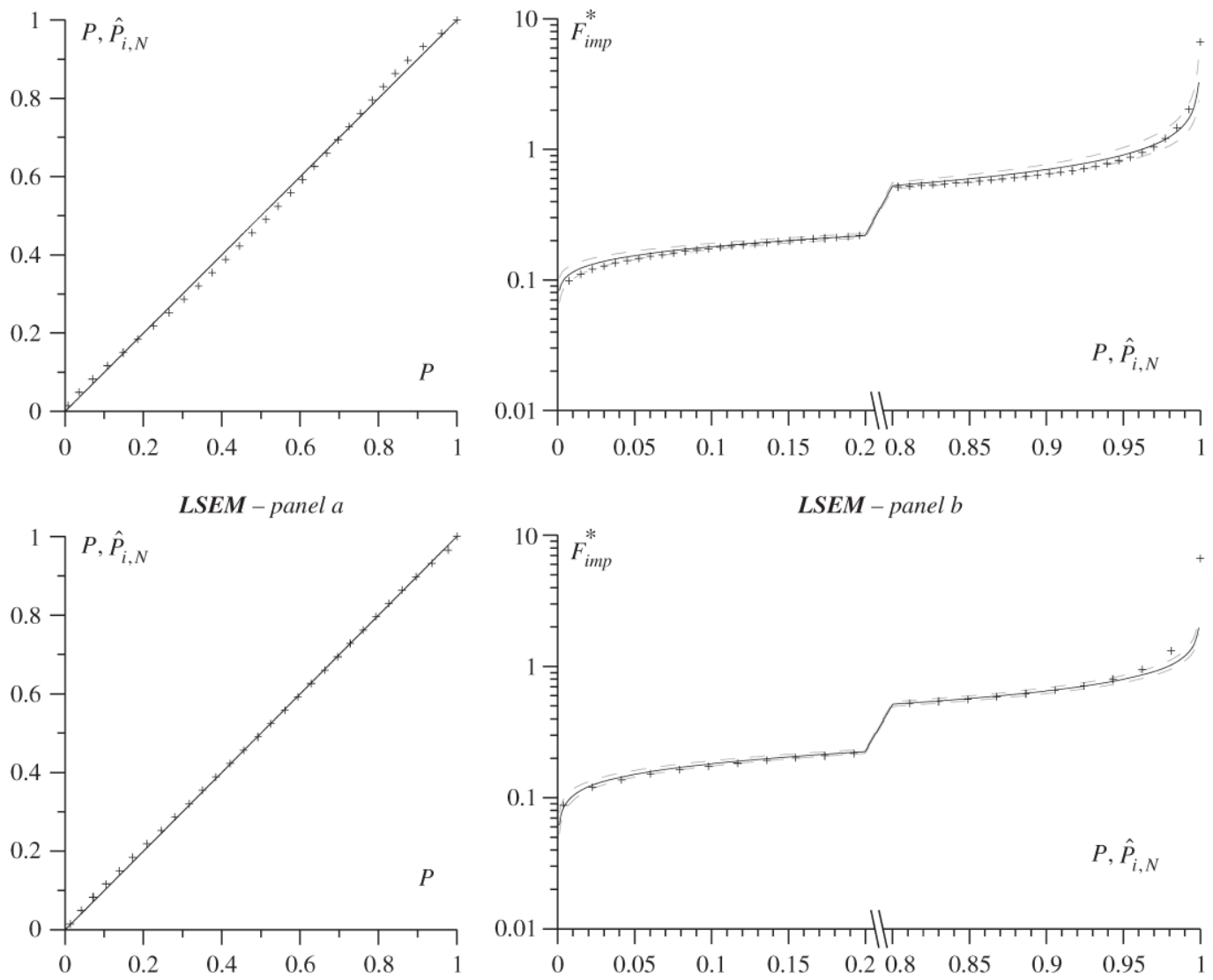

Figure $4 \quad$ Panel $a$ : $P$-P plot, i.e. fitted GEV distribution (solid line) versus sample frequency (symbol +) of non-dimensional impact force; Panel $b$ : quantiles of theoretical cumulative distribution and MonteCarlo simulated confidence interval at $90 \%$ (dashed line) versus quantiles of sample frequency for the nondimensional impact force. Top of each panel $b$ reports the parameter values obtained with the specific fitting techniques

Results obtain for each of the aforementioned fitting techniques are showed in Figure 4, showing the probability-probability plot (panel a) and the comparison between the quantiles of the theoretical nonexceedance probability function, along with their confidence interval at $90 \%$ significance, and the quantiles of the correspondent sample frequency (panel $b$ ). 
The Kolmogorov-Smirnov goodness of fit test rejected the hypothesis that the GEV is the true sample distribution over the whole dataset (sample-size $=12998$ ). As pointed out by Braun (1980) this might be due to the fact that "the hypothesis is rejected because even small deviations from the ideal function are exaggerated when sample sizes are large". One way of dealing with this problem is that of extracting random sub samples of the data and testing goodness of fit on these less numerous samples (Braun, 1980). Figure 5 shows the results obtained by varying the sample size; it is evident that $\mathrm{K}-\mathrm{S}$ test is reasonably satisfied when the sample size is about 800. According to Petruskas and Aagaard (1971), the spreading of a MonteCarlo simulated sample can also be used to describe the confidence related to any chosen quantile. As shown in Figure 4 , for the MLLM and L-moments methods, the sample quantile are always included into the confidence band at $90 \%$ of significance (obtained on the basis of 500 series of MonteCarlo simulated data). Accordingly, it appears that the generalized extreme value distribution fitted both by Maximum LogLikelihood and $L$-moments methods correctly models the non-dimensional impact force maxima. The GEV parameters computed by MLLM read:

$$
\hat{A}=2.80410^{-1}, \hat{B}=1.37610^{-1}, \hat{k}=-2.43810^{-1}
$$

As for the non-dimensional rise times, the results achieved by fitting the ensemble dataset with the GP distribution with the LSEM, the MLLM and the L-moments methods are showed in Figure 6, similarly to Figure 4.

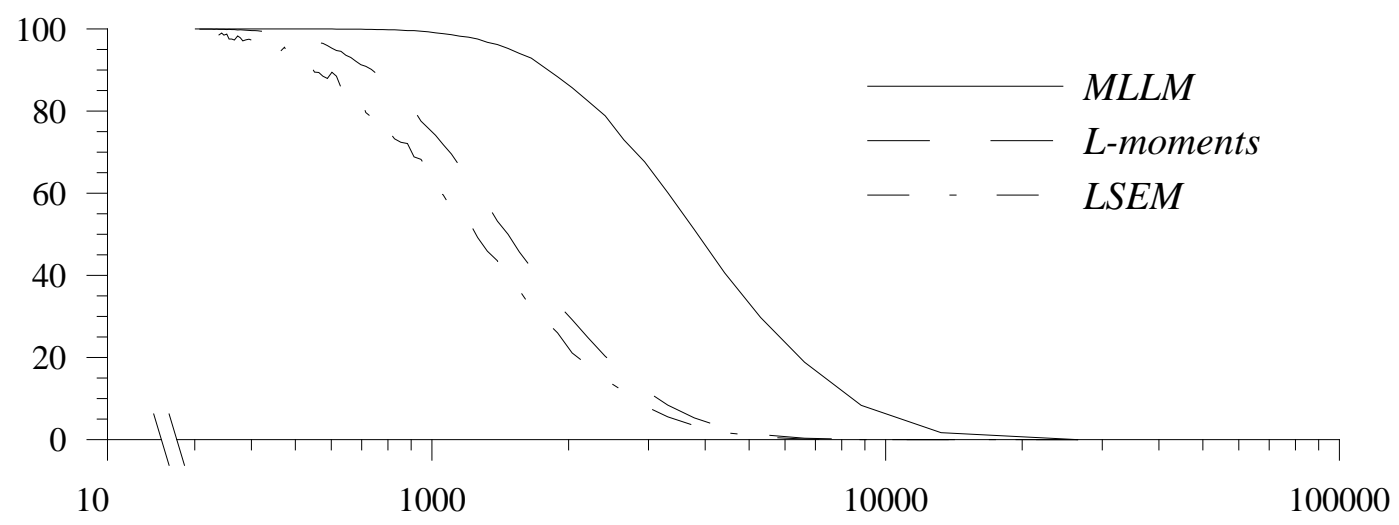

Figure 5 Significance level of the Kolmogorov-Smirnov goodness of fit test performed on impact data sub-set of varying size.

The Kolmogorov-Smirnov goodness of fit test again rejected the hypothesis that the GP is the true sample distribution when the sample-size was 12998 . We therefore proceeded again by taking random sub samples of the total data and performing the goodness of fit Kolmogorov-Smirnov test (Braun, 1980). Figure 7 shows the results obtained by varying the sample size; it is evident that K-S test is satisfied when the sample size is about 400 , with the sample quantiles being included within the $90 \%$ significance confidence band (see Figure 6). The generalized Pareto was therefore considered suitable to model the non-dimensional rise-time probability distribution. The GP parameters fitted by MLLM read:

$$
\hat{\mu}=0.0, \hat{\eta}=2.21410^{-1}, \hat{\kappa}=-1.267
$$




\subsection{Estimation of copula association parameters}

With the aim of identifying the joint probability function, we tested different families of single-parameter bivariate copulas, i.e. functions depending on an unique variable that controls the degree of data dependence. We tested both Archimedean (Nelsen R.B., 2006) and non-Archimedean copulas (Plackett, 1965). Among those tested, the non-Archimedean Plackett model was chosen for its non-symmetrical features; it is defined by the following equations:
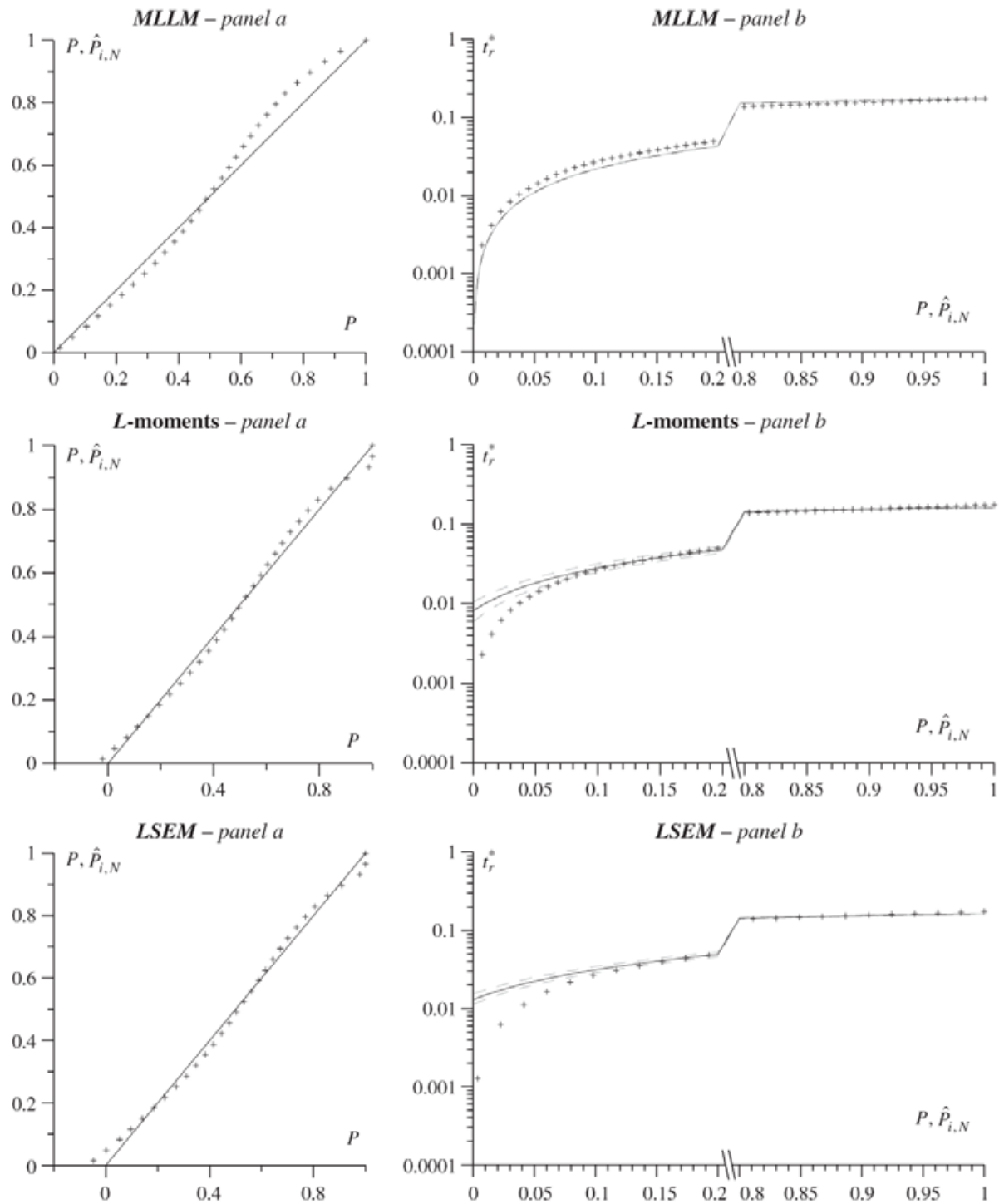

Figure $6 \quad$ Panel a: P-P plot, i.e. fitted GP distribution (solid line) versus sample frequency (symbol +) of non-dimensional rise-time; Panel b: quantiles of theoretical cumulative distribution and MonteCarlo simulated confidence interval at $90 \%$ versus quantiles of sample frequency for non-dimensional rise-time. Top of each panel b reports the parameter values obtained with the specific 


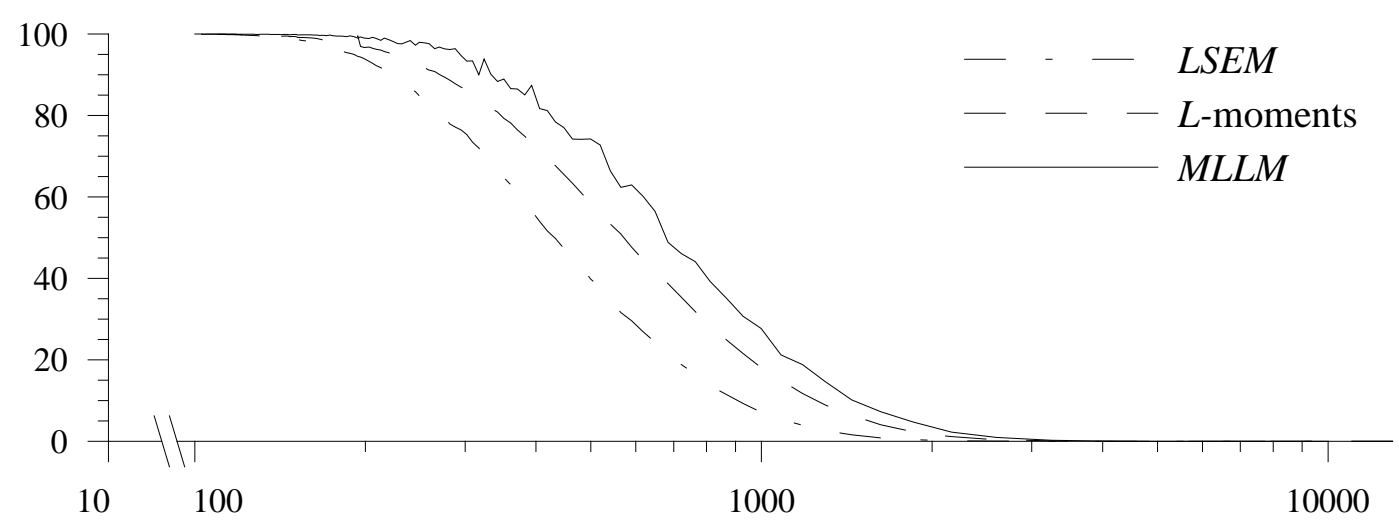

Figure $7 \quad$ Significance level of the Kolmogorov-Smirnov goodness of fit test performed on rise-time data sub-set of varying size

$$
\begin{aligned}
& C(P(x), G(y))=\frac{\Theta-\sqrt{\Theta^{2}-4 \psi(\psi-1) P(x) G(y)}}{2(\psi-1)} \text { if } \psi \neq 1 \\
& C(P(x), G(y))=P(x) G(y) \text { if } \psi=1 \\
& \Theta=1+(\psi-1)[P(x)+G(y)]
\end{aligned}
$$

being $\psi \in(0, \infty)$ the dependence coefficient (for $\psi=1$ the variables are independent, for $\psi \in(0,1)$ the variables have negative correlation, whilst for $\psi \in(1, \infty)$ the variables have positive correlation). The density and conditional distributions are as follow:

$$
\begin{aligned}
& c(P(x), G(y))=\frac{\psi\{(\psi-1)[P(x)+G(y)-2 P(x) G(y)]+1\}}{\sqrt{\left\{\Theta^{2}-4 \psi(\psi-1) P(x) G(y)\right\}^{3}}} \\
& C_{G}(P(x) \mid G(y)=\xi)=\frac{1}{2}\left\{1-\frac{1+P(x)(\psi-1)-\xi(\psi+1)}{\sqrt{\Theta^{2}-4 \psi(\psi-1) P(x) \xi}}\right\} \\
& C_{P}(G(y) P(x)=\zeta)=\frac{1}{2}\left\{1-\frac{1+\zeta(\psi-1)-G(y)(\psi+1)}{\sqrt{\Theta^{2}-4 \psi(\psi-1) \zeta G(y)}}\right\}
\end{aligned}
$$

The computation of the dependence parameters $\psi$ has been carried out using the Maximum Log-Likelihood method, i.e. maximizing the following expression

$$
\sum_{i=1}^{N} \log \left[c\left(P\left(F_{i m p}^{*} ; \hat{A}, \hat{B}, \hat{k}\right), G\left(t_{r}^{*} ; \hat{\mu}, \hat{\eta}, \hat{\kappa}\right), \psi\right)\right]
$$

The maximisation was performed using the "Complex" method solving Equation 40 with marginal parameters given by Equations 32 and 33. The association parameter was found to be:

$$
\hat{\psi}=6.390 \cdot 10^{-3}
$$


The corresponding data correlation structure is presented in Figure 8.

Using the estimated parameter vectors of the GEV and GP distributions (Equations 32 and 33) along with the computed values of the association parameter, we can obtain the cumulate non-exceedance and density probabilities (Figure 9) as well as the conditional probability of impact maximum given its rise-time (Figure 10). Figures 9 and 10 show a good agreement of the observed dataset with the fitted probability model and confirm the nearly perfect negative correlation between the impact maxima and the rise-time.

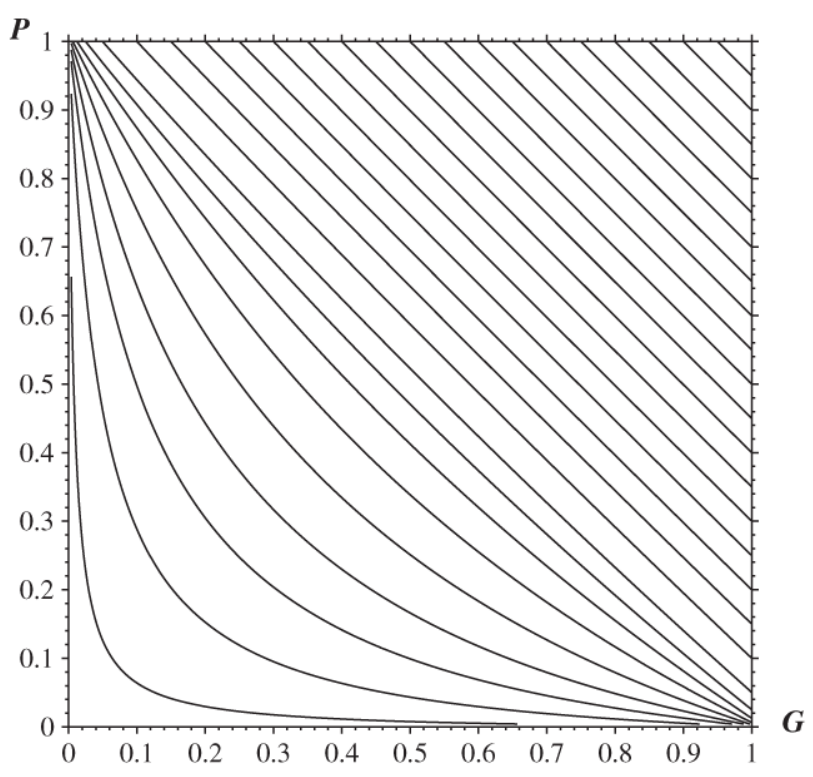

Figure 8 Correlation structure obtained by using the Plackett copula given by Equation 34, with the association parameter equal to $6.39010^{-3}$.
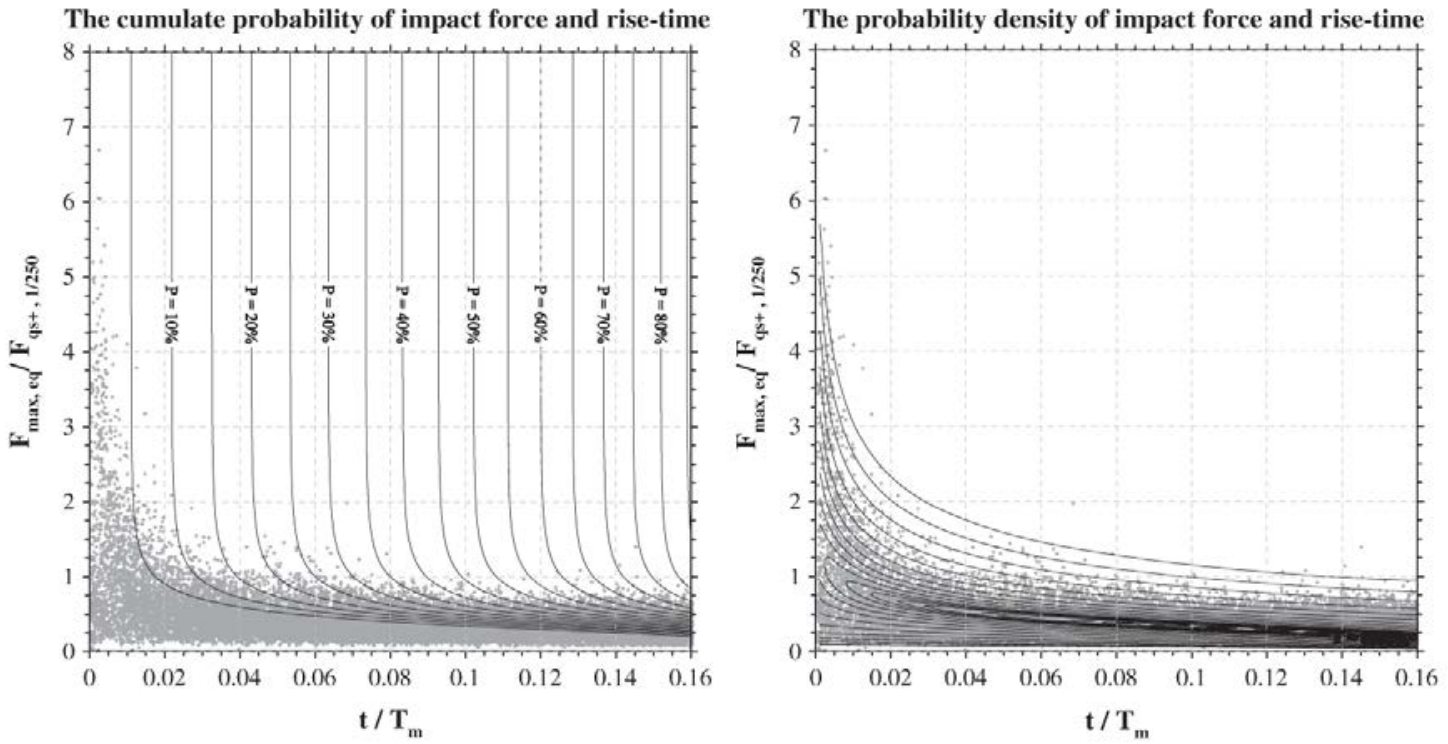

Figure $9 \quad$ The cumulate non-exceedance probability and the density probability obtained by using the Plackett copula with the correlation parameter equal to $6.39010^{-3}$. 


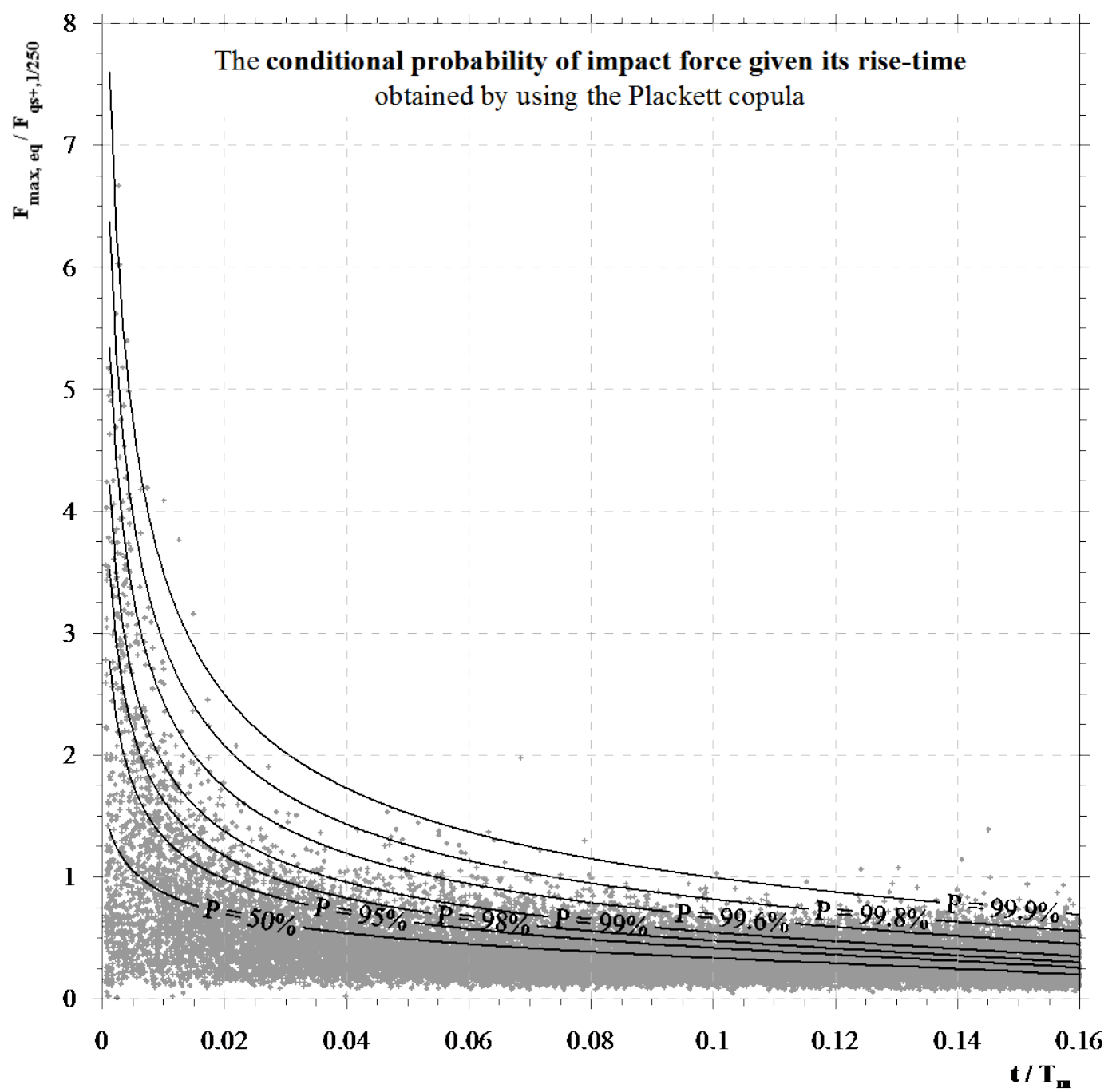

Figure $10 \quad$ The conditional probability of impact force given its rise-time obtained by using the Plackett copula with the association parameter equal to $6.39010^{-}$

The stochastic correlation between rise-time and impact-force maximum can now be expressed by a noninvertible function of the assigned probability level $(\Omega)$ :

$$
e^{-\left(1-\hat{k} \hat{B}^{-1} F_{i m p}^{*}-\hat{A}\right)^{1 / \hat{k}}}=\frac{(1-2 \Omega)}{(\hat{\psi}-1)} \sqrt{\Lambda}+\frac{(1+\hat{\kappa} \hat{\eta} \vartheta)^{-1 / \hat{\kappa}}(\hat{\psi}+1)+2}{(\hat{\psi}-1)}
$$

where $F_{\text {imp }}^{*}$ is the impact-force value corresponding to the given value $\vartheta$ of the non-dimensional rise-time $t_{r}^{*}$ and $\Lambda$ is given by: 


$$
\Lambda=\left\{1+(\hat{\psi}-1)\left[2+e^{-\left(1-\hat{k} \hat{B}^{-1} F_{i m p}^{*}-\hat{A}\right)^{1 / \hat{k}}}-(1+\hat{\kappa} \hat{\eta} \vartheta)^{-1 / \hat{\kappa}}\right]\right\}^{2}-4 \hat{\psi}(\hat{\psi}-1) \frac{1+e^{-\left(1-\hat{k} \hat{B}^{-1} F_{i m p}^{*}-\hat{A}\right)^{1 / \hat{k}}}}{(1+\hat{\kappa} \hat{\eta} \vartheta)^{1 / \hat{\kappa}}-1}(1+\hat{\kappa} \hat{\eta} \vartheta)^{1 / \hat{\kappa}}
$$

Which can be solved using the Newton-Raphson numerical method.

With the aim to simplify the estimation of Equation 43 , we proceeded as follows: first we fixed a series of probability level $\Omega$ (in accordance to statistical and coastal engineering standards) and obtained a curve corresponding to each probability level; then we fitted a power law, similar to Equation 5 , to each of the obtained curves. Results of the fitting procedure are summarised in Table 3 together with the maximum relative error (in percentage). Although very simple, the use of power law as fitting curve leads to unsatisfactory adaptation to the theoretical conditional probability, particularly in the region of the most violent impacts (Figure 11). For this reason, with the aim of reducing the relative error while using a simplified expression, we tried a series of alternative functions, among those tested, the following was found to provide the best compromise between fitting performances and ease of use:

$$
F_{i m p}^{*}=a_{1}\left(\frac{t_{r}^{*}-b_{1}}{c_{1}}\right)^{d_{1}}+a_{2}\left(\frac{t_{r}^{*}-b_{2}}{c_{2}}\right)^{d_{2}}
$$

where $a_{1,2}, b_{1,2}, c_{1,2}, d_{1,2}$ are fitting parameters summarised, for each probability level, in Table 4 , together with their corresponding maximum relative error. The achieved improvement is also confirmed in Figure 11.

Table 3. Dynamic characteristics of typical prototype caisson breakwaters

\begin{tabular}{lc}
\hline \multicolumn{1}{c}{ Researcher } & Period of vibration (s) \\
Muraki, 1966 & $0.20 \div 0.40$ \\
Ming et al., 1988 & 0.26 \\
Schmidt et al., 1992 & $0.15 \div 0.60$ \\
Lamberti and Martinelli, 1998 & $0.15 \div 2.00$ \\
\hline
\end{tabular}

Table 4. Coefficients $a$ and $b$ in Equation 5 at different level of non-exceeding joint-probability levels

\begin{tabular}{cccc}
\hline Non-exceedance level [\%] & a & b & Err rel [\%] \\
99.9 & 0.479 & -0.411 & $25.23 \%$ \\
99.8 & 0.392 & -0.415 & $25.57 \%$ \\
99.6 & 0.324 & -0.417 & $25.66 \%$ \\
99.5 & 0.307 & -0.417 & $25.61 \%$ \\
99.0 & 0.262 & -0.414 & $25.21 \%$ \\
98.0 & 0.231 & -0.405 & $24.50 \%$ \\
95.0 & 0.208 & -0.386 & $24.01 \%$ \\
\hline
\end{tabular}



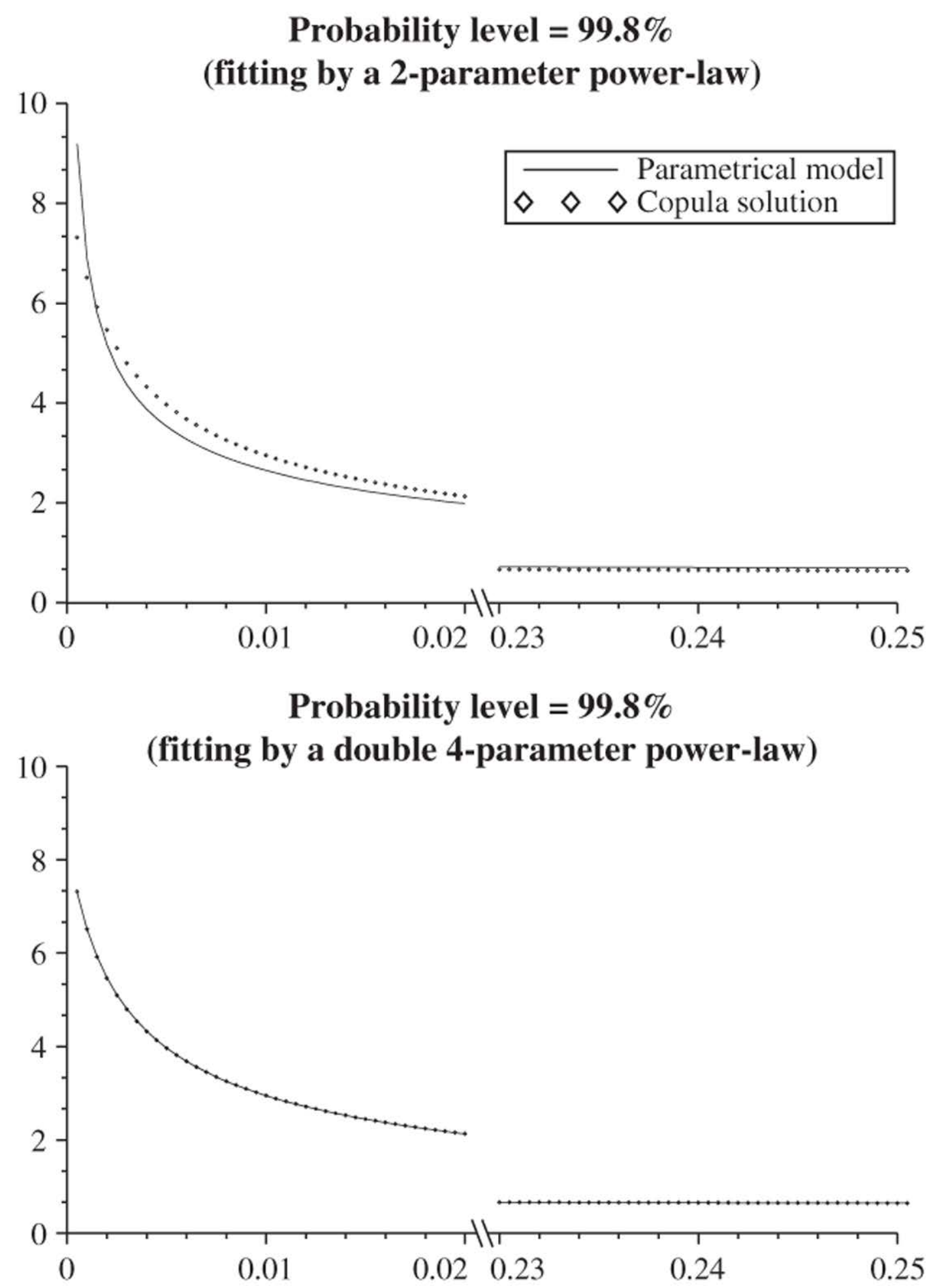

Figure $11 \quad$ Normalised static-equivalent design load $F_{\text {eq }} / F_{\text {Goda }}(-0-)$ corresponding to example breakwaters in Figure 9 for increasing non-exceedance levels between 95\% and 99.8\%. In the plots are also represented predictions by Goda (1974), solid line and Takahashi et al. (1994), dashed line. 


\section{Dynamic analysis of caisson breakwaters}

Being structurally relatively simple, the dynamics of caisson breakwater is usually driven by the characteristics of the soil foundation. In the past, several authors explored the dynamic behaviour of caisson breakwaters subjected to impulsive wave loading by means of basic mass-spring-dashpot multi-degree of freedom (MDOF) linear system models (see, among the others: Oumeraci and Kortenhaus, 1994; Goda, 1994, Pedersen, 1997 and Lamberti and Martinelli, 1998). Comprehensive reviews of the state of the art of foundation design of caisson breakwaters can be found in de Groot et al. (1996) and Oumeraci et al. (2001).

In the following, the relative importance of impact rise-time and pulse shape on the effective load to be used in design of caisson breakwaters is discussed briefly, based on the analogy of the dynamics of caisson breakwaters with that of a single degree of freedom (SDOF) linear system. In fact, despite its simplicity, the model has been found to be suitable for the initial estimation of the amplification factor for use in early feasibility studies (more details are given in Cuomo, 2005).

\subsection{Dynamic response of a SDOF system to pulse excitation and shock spectrum.}

For a linear SDOF system of known mass $(M)$, stiffness $(K)$ and viscous damping $(D)$, subject to a force $f(t)$ arbitrarily varying in time, the solution to the equation of motion at time $t$ can be expressed as the sum of the responses up to that time by the convolution integral:

$$
u(t)=\frac{1}{M \omega_{D}} \int_{0}^{t} f(\tau) \cdot e^{-\xi \omega n(t-\tau)} \cdot \sin \left[\omega_{D}(t-\tau)\right] d \tau
$$

Where $\omega_{n}=\sqrt{K / M}$ and $\xi=D / 2 M \omega_{n}$ is the damping ratio and $\omega_{D}=\omega_{n} \sqrt{1-\xi^{2}}$. Equation 45 is known as Duhamel's integral and, together with the assigned initial conditions, provides a general result for evaluating the response of a linear SDOF system subject to arbitrary time-varying force. In general, the dynamic response of a SDOF system will have to be evaluated numerically by solving Equation 45 in time. Results shown in the following have been obtained by integrating numerically Equation 45 by means of a time-stepping method based on the interpolation of excitation (Chopra, 2001). At each $\mathrm{i}^{\text {th }}$ time-step, the variation of the exciting force $f(t)$ over the time interval $0 \leq \tau \leq \Delta t$ is assumed to be linear, so that $f\left(t_{i}+\Delta t\right)=f\left(t_{i}\right)+\Delta f_{i} / \Delta t \cdot \tau$ and the displacement of the system $\Delta u(t)$ results expressed by the sum of three contributions, respectively: the free vibration due to the initial displacement $u_{i}$ and velocity $\dot{u}_{i}$ at $\tau=0$, the response to a step force $f_{i}$ constant within $0 \leq \tau \leq \Delta t$ supposed to be applied on the system at rest $\left(u_{i}=\dot{u}_{i}=0\right)$ and the response to a ramp force $\left(\Delta f_{i} / \Delta t_{i}\right) \cdot \tau$ which is assumed to act on the system at rest.

The dynamic amplification factor $(\Phi)$ can be defined as the ratio of the maximum displacement of the system in time $u(t)_{\max }$ and the displacement $u_{0}$ of the same system due to the static application of the maximum force $F_{\max }:$ 


$$
\Phi=\frac{u(t)_{\max }}{u_{0}}
$$

where $u_{0}=F_{\max } / K$.

The procedure described above has been used to investigate the dynamic response of SDOF systems to simplified time-history loads whose general form reads:

$$
F(t)=F_{\text {max }} \cdot f\left(t_{r}, t_{d}, t\right)
$$

where $F_{\max }$ is the maximum force, $t_{r}$ the rise time and $t_{d}$ the total pulse duration and $t$ the time. Equation 47 has been used to describe the triangular pulse time-history load as follows:

$$
f\left(t_{r}, t_{d}, t\right)=\left\{\begin{array}{cc}
\left(t / t_{r}\right) & t \leq t_{r} \\
{\left[1-\left(t-t_{r}\right) /\left(t_{d}-t_{r}\right)\right]} & t_{r}<t \leq t_{d} \\
0 & t>t_{r}
\end{array}\right.
$$

Depending on the values of $t_{r}$ and $t_{d}$ in Equation 45 , the following particular cases can be obtained:
a. asymmetrical triangular pulse;
b. right-angled triangular pulse;
c. symmetrical triangular pulse;
d. step force with finite rise-time;

Case $a$ is the most general, cases $b-d$ are obtained entering Equation 48 respectively with $t_{d}=t_{r}$, $t_{d}=2 \cdot t_{r}$ and $t_{d}=\infty$.

For a SDOF system of given damping ratio, subject to pulse excitation, the deformation of the system in time $u(t)$, and therefore $\Phi$, only depend on the pulse shape and on the ratio between the pulse rise-time $\left(t_{r}\right)$ and the period of vibration of the system $\left(T_{0}=2 \pi / \omega\right)$ (Chopra, 2001). For a given shape of the exciting pulse, $\Phi$ can therefore be regarded as a function of the ratio $t_{r} / T_{0}$ only. The variation of the $\Phi$ with $T_{0}$ (or a related parameter) is named "response spectrum", when the excitation consists of a single pulse, the term "shock spectrum" is also used. Example shock spectra are given in Figure 12 for pulse shapes obeying Equation 48 and with total duration time $\left(\mathrm{t}_{\mathrm{d}}\right)$ respectively equal to $\mathrm{t}_{\mathrm{r}}$ (left), $2 \mathrm{t}_{\mathrm{r}}$ (center) and $3 \mathrm{t}_{\mathrm{r}}$ (right). 

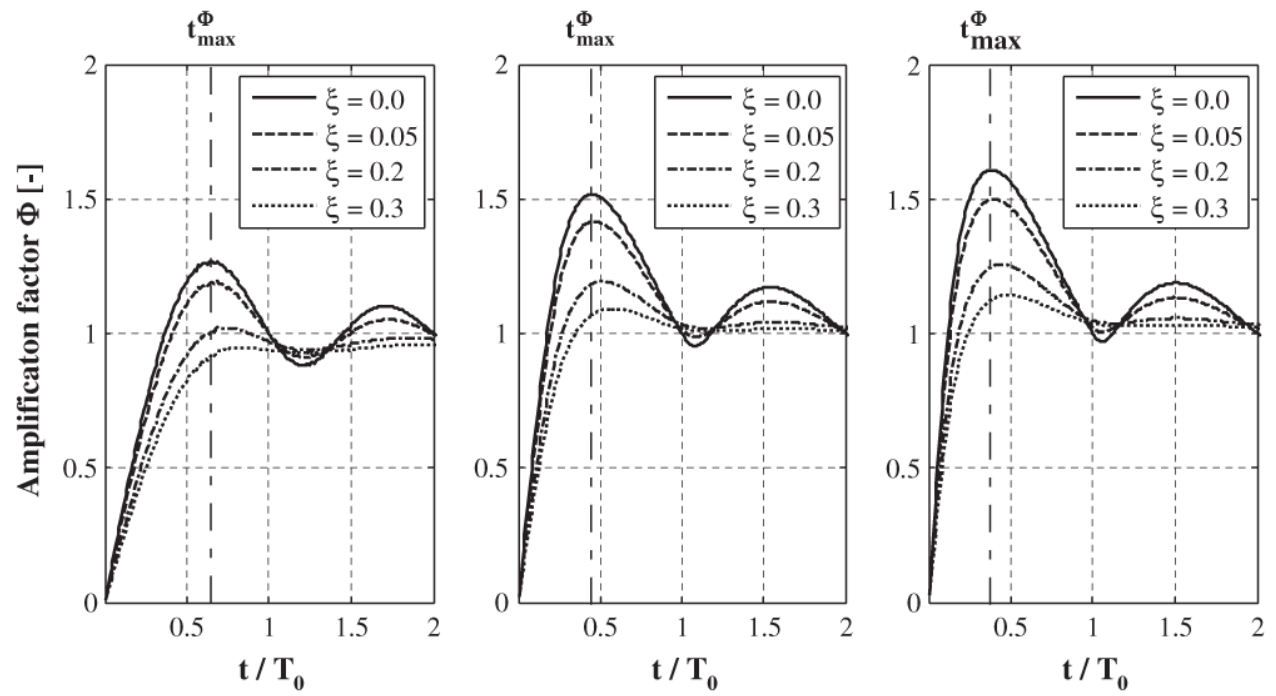

Figure 12 Example shock spectra for a linear SDOF system subject to triangular pulse (Eq. (45)) having total duration time $\left(t_{\mathrm{d}}\right)$ respectively equal to $t_{\mathrm{r}}$ (left), $2 t_{\mathrm{r}}$ (center) and $3 t_{\mathrm{r}}$ (right)

When a system is subject to an harmonic excitation at or near resonance, the energy dissipated by damping is significant. On the contrary, when the system is excited by a single pulse, the energy dissipated by damping is much smaller and the relative importance of damping on maximum displacement decreases. This is confirmed in Figure 12, where shock spectra of a damped SDOF system ( $\xi=0.05$, dashed line) is superimposed to the one corresponding to the equivalent un-damped system ( $\xi=0$, solid line).

Nevertheless, for maritime structures, damping can be much larger than for other civil structures (i.e. $\xi>>$ 0.05), due to the high dissipative role played by both water (Petersen, 1997) and soil foundation (Wolf, 1988) and although being generally safe, not taking into account the effect of damping when assessing effective design load might result in a significant overestimation of wave-induced loads. This is demonstrated by results in Figure 12 from further computations assuming $\xi=0.2$ (dashed dotted line) and $\xi=0.3$ (dotted line).

The effective pulse shape of the wave-induced load depends on both the incoming wave kinematics and the dynamic characteristics of the structure, nevertheless, in order to facilitate the analysis of the dynamic response of caisson breakwater to pulse excitation, time-histories recorded during physical model tests were schematised as simplified pulses. An example idealised load-history is superimposed on an original signal in Figure 2, the triangular spike is characterized by the maximum reached by the signal during loading $\left(P_{\max }\right)$, the time taken to get to $P_{\max }$ from $0\left(t_{r}\right)$ and back $\left(t_{d}\right)$. The shaded area in Figure 2 represents momentum transfer to the structure during the impact, the impulse. Such schematisation has encountered the favour of many authors in the past and results in this paper confirm its suitability for simplified but meaningful timehistory analysis.

Moving from previous (Schmidt et al. 1992, Oumeraci et al. 1993 and Hattori et al. 1994) and new observations, the following association between breaking wave types and shock spectra in Figure 12 has been suggested (Cuomo, 2005):

- Flip through

- Vertical wave front

- Plunging wave with air pocket
$\Rightarrow \quad$ asymmetrical triangular pulse;

$\Rightarrow \quad$ right-angled triangular pulse;

$\Rightarrow \quad$ symmetrical triangular pulse. 
Given the variability of the loading process, the above shall be nevertheless taken as an indicative guideline only; in the general case, an initial estimate of $t_{d}$ in Equation 48 can be obtained by means of Equation 10.

\subsection{Dynamic characteristics of prototypes}

Prototype measurements of the dynamic characteristics of caisson breakwaters have been assessed by Muraki (1966), Ming et al. (1988), Schmidt et al. (1992) and Lamberti and Martinelli (1998). The estimates given by the authors are summarised in Table 5 .

Table 5. Coefficients of Equation 41 at different level of non-exceeding joint-probability levels

\begin{tabular}{cccccccccc}
\hline $\begin{array}{c}\text { Non-exceedance } \\
\text { level [\%] }\end{array}$ & $\mathbf{a}_{\mathbf{1}}$ & $\mathbf{b}_{\mathbf{1}}$ & $\mathbf{c}_{\mathbf{1}}$ & $\mathbf{d}_{\mathbf{1}}$ & $\mathbf{a}_{\mathbf{2}}$ & $\mathbf{b}_{\mathbf{2}}$ & $\mathbf{c}_{\mathbf{2}}$ & $\mathbf{d}_{\mathbf{2}}$ & $\begin{array}{c}\text { Err } \\
\text { rel } \\
{[\%]}\end{array}$ \\
99.9 & 0.013 & -1.023 & 0.410 & 2.023 & 0.457 & -0.002 & 0.502 & -0.537 & 0.42 \\
99.8 & 0.035 & -0.682 & 0.588 & 1.853 & 0.348 & -0.002 & 0.613 & -0.534 & 0.29 \\
99.6 & 0.044 & -0.622 & 0.811 & 2.058 & 0.415 & -0.002 & 0.328 & -0.529 & 0.10 \\
99.5 & 0.042 & -0.581 & 0.822 & 2.074 & 0.377 & -0.002 & 0.359 & -0.526 & 0.05 \\
99.0 & 0.008 & -0.878 & 0.702 & 2.411 & 0.356 & -0.001 & 0.306 & -0.514 & 0.29 \\
98.0 & 0.003 & -1.186 & 0.986 & 2.327 & 0.419 & -0.001 & 0.183 & -0.491 & 0.45 \\
95.0 & 0.000 & -1.159 & 0.915 & 2.302 & 0.387 & -0.001 & 0.170 & -0.460 & 2.06 \\
\hline
\end{tabular}

Differences in values given in Table 5 is mainly due to the fact that such estimates correspond to caisson breakwaters structurally significantly different. In fact, while periods of vibration by Muraki and Ming were derived from analysis of relatively "small" caisson installed in relatively shallow water, those referred to by Schmidt et al and Lamberti and Martinelli correspond to much more massive caisson units in relatively deep water. Moreover, the wider range of estimates given by Lamberti and Martinelli is due to the fact that the authors considered modes of vibration that involve motion of adjacent caisson units, and thus mobilise a larger amount of mass.

\subsection{Scaling}

For practical use, data from physical model tests need back-scaling to prototype. As stated earlier in this work, it is widely recognised that use of Froude similarity for back-scaling wave impact recorded at model scale leads to overestimation of impact maxima and underestimation of impact rise times, conserving total wave impulse. Bearing this in mind, we scaled wave impact maxima following the approach in Cuomo et al. (2010), based on the "compression law" originally proposed by Bagnold (1939) and successively extended by Mitsuyatsu (1966), Lundgren (1969) and Takahashi et al. (1985). 


\section{Proposed method for the evaluation of statically equivalent design load}

For feasibility study, a first estimate of the statically equivalent impact load to be assumed in the design can be evaluated by means of the simplified procedure described in the following:

1. Condense the structure into a linear SDOF system evaluating its dynamic parameters (mass, stiffness and damping) as functions of the dynamic characteristics of the structure, its foundation and of the water level in front of caisson;

2. Select the pulse shape (asymmetrical triangular pulse, right-angled triangular pulse or symmetrical triangular pulse) corresponding to the breaker type (flip through, vertical wave front or plunging wave with air pocket) that is expected to occur in front of the structure as a function of the geometrical characteristics of the structure and its foreshore. When no further information is available, a symmetrical triangular pulse (Equation 48, case b) represents a reasonable choice. For the sake of simplicity, in the following we assume the pulse to have such symmetrical shape;

3. For the selected pulse shape, evaluate the dynamic amplification factor $\Phi$ of the system for different values of the ratio $\mathrm{t}_{\mathrm{r}}{ }^{\Phi}=\mathrm{t}_{\mathrm{r}} / \mathrm{T}_{0}$ and evaluate $\Phi_{\max }=\max \left[\Phi\left(\mathrm{t}_{\mathrm{r}}{ }^{\Phi}\right)\right]$ for $0<\mathrm{t}_{\mathrm{r}}{ }^{\Phi}<2$ (we assume here every load applied for longer then $2 \mathrm{~T}_{0}$ to be felt as quasi-static by the structure) to identify severest combination of wave impact maximum and rise time to be used in design;

4. Assume a non-exceedance joint-probability level for the calculation. For simplicity, parameters $a$ and $b$ in Equation 5 have been fit to iso-joint probability contour line corresponding to non-exceeding levels equal to: $95 \%, 98 \%, 99 \%, 99.5 \%, 99.6 \%, 99.7 \%$ and $99.8 \%$; results are summarized in Table 3;

5. Evaluate $\mathrm{F}^{*}=\mathrm{F}_{\mathrm{imp}} / \mathrm{F}_{\mathrm{h}, \mathrm{qs}+(1 / 250)}$ in Equation 5 for $\mathrm{t}_{\mathrm{r}}=\mathrm{t}_{\mathrm{r}, \max }^{\Phi} \mathrm{T}_{0} / \mathrm{T}_{\mathrm{m}}\left(\mathrm{t}_{\mathrm{r}, \text { max }}^{\Phi}\right.$ being the value of $\mathrm{t}_{\mathrm{r}}$ that maximise $\Phi$, Figure 12);

6. Evaluate the appropriate scaling factor $\left(\lambda_{\mathrm{s}}\right)$ using procedure in Cuomo et al. (2010) as a function of the Bagnold number at prototype scale;

7. Compute the quasi-static load $\mathrm{F}_{\mathrm{h}, \mathrm{qs}+(1 / 250)}$ acting on the structure using prediction method by Goda (1974) that is, assuming $\alpha_{2}, \alpha_{1}=0$ in the expressions given in Goda (2000) and Takahashi et al. (1994);

8. Evaluate the static equivalent design load as: $F_{\text {eq }}=\lambda_{s} F_{h, q s+(1 / 250)} F^{*} \Phi_{\max }$.

\section{Example calculations}

Goda $(1973,1974)$ gave a detailed description of documented damages to breakwaters in Japan together with synthetic information on wave conditions at the site during catastrophic events. Among documented failure, we chose the following example cases (Figure 13):

1. Hocinoue Port breakwater (10th section);

2. Kobe Port breakwater;

3. Onahama Port breakwater;

4. Yokohama Port breakwater;

For the four cases above, we schematized the structure as a SDOF system having synthetic dynamic characteristics given in Table 6 . Values of dynamic characteristics ( $K$ and $C$ ) of the soil foundation have been evaluated according to Wolf (1988). A more detailed description of the procedure adopted for the estimation 
of the dynamic characteristics to be used in the dynamic analysis of caisson breakwater is given in Cuomo et al. (in review). Wave conditions recorded at the site are summarized in Table 7.

HACHINOHE PORT - HATTARO HARBOR-

(b) 10 th Section

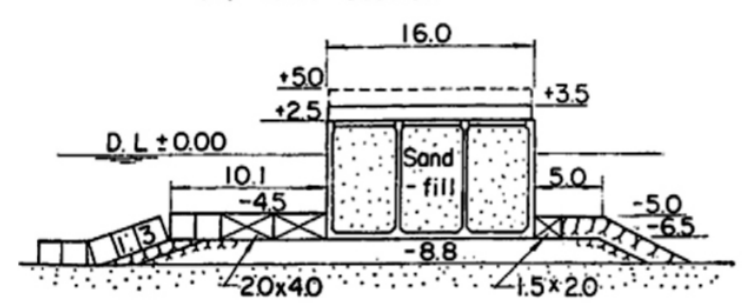

ONAHAMA PORT

(a) Second Breakwater (A-Section)

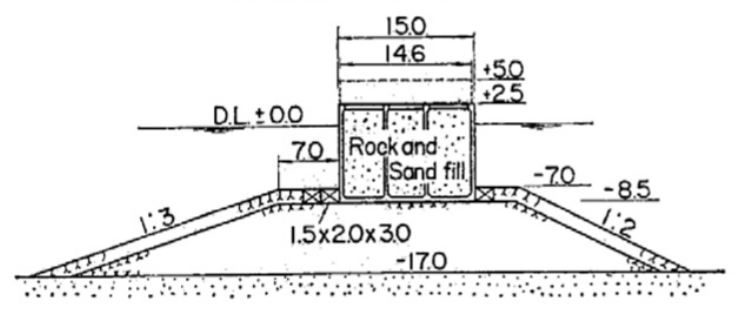

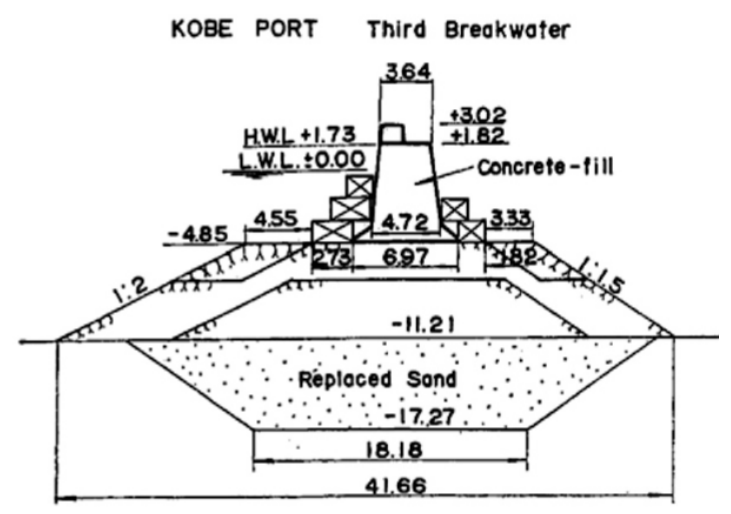

YOKOHAMA PORT Outer Breakwoter

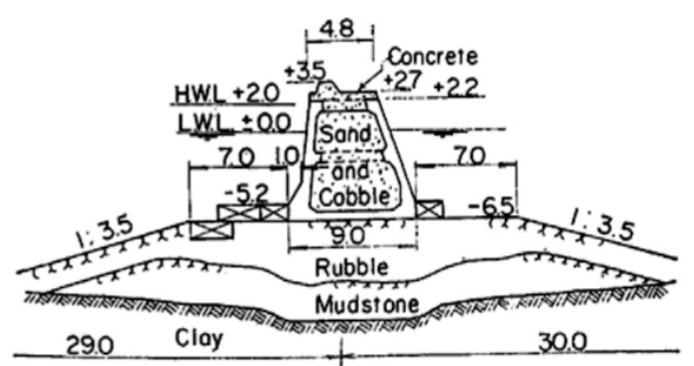

Figure 13 Example breakwater cross sections used in the application of the present methodology to real case study (courtesy of Prof; Y. Goda)

Table 6 .

Dynamic characteristics of equivalent mass-spring-dashpot single degree of freedom system

\begin{tabular}{|c|c|c|c|c|}
\hline Breakwater & $\begin{array}{c}\text { M } \\
\text { [tons] }\end{array}$ & $\begin{array}{c}\mathrm{K} \\
{[\mathrm{kN} / \mathrm{m}]}\end{array}$ & $\begin{array}{c}\text { D } \\
{[\mathrm{kN} \mathrm{s} / \mathrm{m}]}\end{array}$ & $\begin{array}{l}\mathbf{T}_{\mathbf{0}} \\
{[\mathbf{s}]}\end{array}$ \\
\hline Hachinohe & 1216 & $6.510^{6}$ & $63.010^{3}$ & 0.18 \\
\hline Kobe & 3574 & $13.710^{6}$ & $153.710^{3}$ & 0.19 \\
\hline Onahama & 3483 & $11.810^{6}$ & $128.110^{3}$ & 0.21 \\
\hline Yokohama & 2009 & $9.610^{6}$ & $85.910^{3}$ & 0.19 \\
\hline
\end{tabular}

Table 7 .

Wave conditions at the site and corresponding Bagnold number

\begin{tabular}{cccccc}
\hline Breakwater & $\mathbf{H}_{\mathbf{1} / \mathbf{3}}$ & $\mathbf{H}_{\mathbf{m a x}}$ & $\mathbf{T}_{\mathbf{1 / 3}}$ & $\mathbf{T}_{\mathbf{m}}$ & $\mathbf{B g}$ \\
& {$[\mathbf{m}]$} & {$[\mathbf{m}]$} & {$[\mathbf{s}]$} & {$[\mathbf{s}]$} & {$[-\mathbf{]}$} \\
Hachinohe & 6.1 & 7.6 & 11.5 & 10.5 & 0.446 \\
Kobe & 3.3 & 5.9 & 6.0 & 5.5 & 0.418 \\
Onahama & 5.5 & 9.4 & 10.0 & 9.1 & 0.574 \\
Yokohama & 3.5 & 6.3 & 7.3 & 6.6 & 0.445 \\
\hline
\end{tabular}

For simplicity, we use here the approximate expression for $\mathrm{F}^{\star}$ in Equation 5, together with parameters $a$ and $b$ in Table 3. 
The normalised static equivalent design load $\mathrm{F}_{\mathrm{eq}} / \mathrm{F}_{\mathrm{qs}+, 1 / 250}$ corresponding to example cases in Table 6 (by means of $T_{0}$ ) and wave condition in Table 7 (by means of $T_{m}$ ) can now be evaluated for non-exceedance joint probability levels in Tab 4. Results are plotted in Figure 14 as a function of dimensionless rise time $t_{r} / T_{m}$. For the example cases used in this application, critical rise times fall within the range $0.001 \mathrm{~T}_{\mathrm{m}}<\mathrm{t}_{\mathrm{r}}<0.005$ $\mathrm{T}_{\mathrm{m}}$. The static equivalent design load can now be evaluated by multiplying quasi-static design load by Goda (1974) for maxima of $F_{\text {eq }} / F_{\mathrm{qs}^{+}, 1 / 250}$ as a function of the non-exceedance joint probability level.

As expected, the dynamic response of the caisson significantly reduces wave impacts having duration $t_{d}<<$ $T_{0}$ while amplifying impact pressures with duration comparable to the period of oscillation of the structure. Impact pressures having duration $t_{d} \gg T_{0}$ are "quasi-statically" applied to the superstructure and therefore not affected by its dynamic response. Since their magnitude is smaller than that of pulsating loads at 1/250 significance level $\left(\mathrm{F}_{\mathrm{imp}} / \mathrm{F}_{\mathrm{h}, \mathrm{qs}+(1 / 250)}<1\right)$ they have little effects on the stability of the breakwater. And the caisson should be design to withstand pulsating loads predicted by well established methods (Goda, 2000).

Results are given in Table 8 in terms of horizontal (shoreward) design wave load at non-exceedance level $99.6 \%$ (that is, at $1 / 250$ significance level).

Table 8. Horizontal (shoreward) design load

\begin{tabular}{cccc}
\hline Breakwater & $\begin{array}{c}\text { Goda } \\
{[\mathbf{k N}]}\end{array}$ & $\begin{array}{c}\text { Takahashi } \\
{[\mathbf{k N}]}\end{array}$ & $\begin{array}{c}\text { Present } \\
\text { method } \\
{[\mathbf{k N}]}\end{array}$ \\
\hline & $\mathbf{F}_{\mathbf{1 / 2 5 0}}$ & $\mathbf{F}_{\mathbf{1} / \mathbf{2 5 0}}$ & $\mathbf{9 9 . 6} \mathbf{\%}$ \\
Hachinohe & 818 & 1027 & 1069 \\
Kobe & 277 & 532 & 300 \\
Onahama & 1048 & 1700 & 1046 \\
Yokohama & 439 & 647 & 503 \\
\hline
\end{tabular}



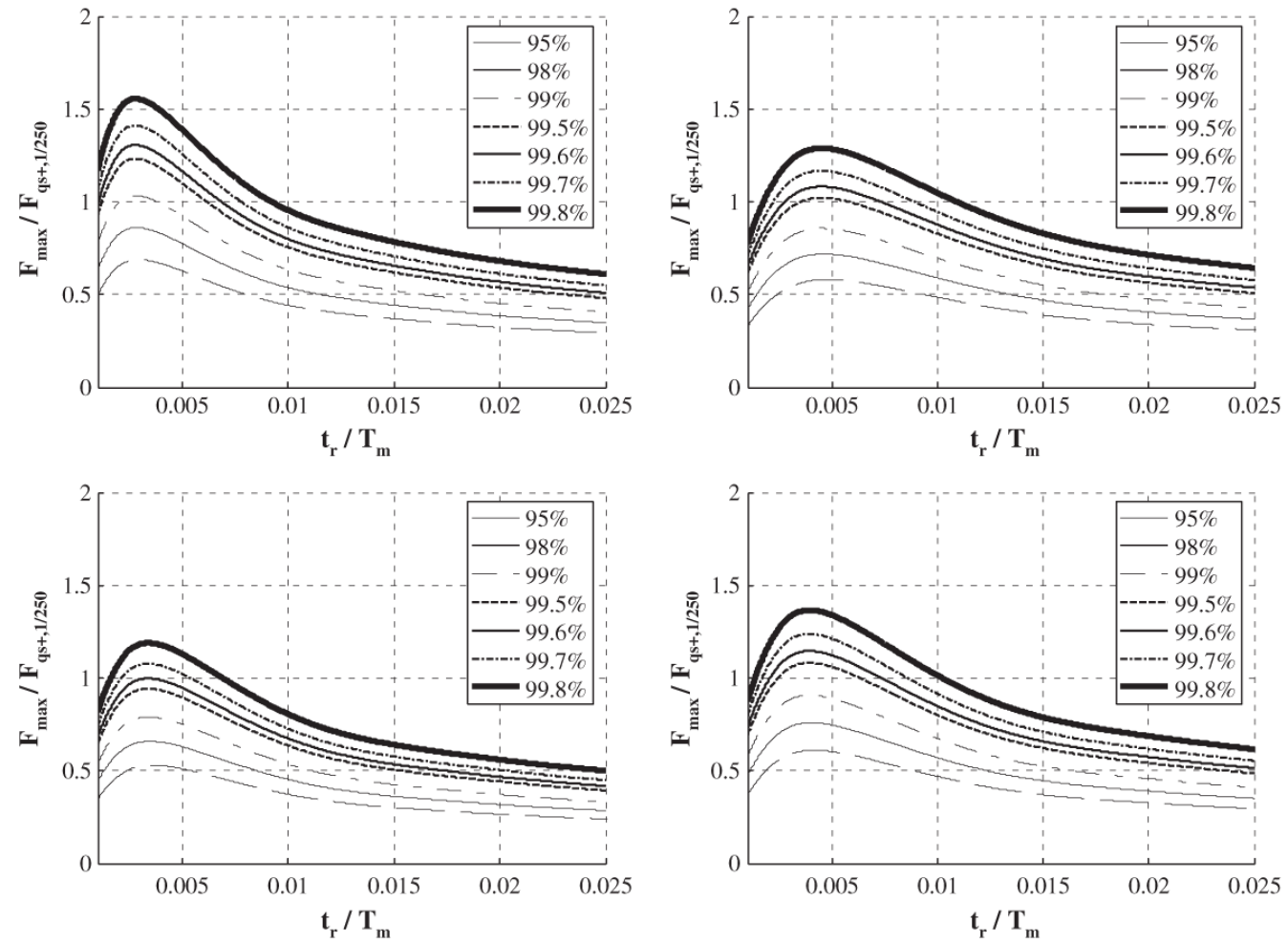

Figure 14 Normalised static-equivalent design load $F_{\text {eq }} / F_{\mathrm{qS}+, 1 / 250}$ corresponding to example breakwaters in Figure 9 , as a function of the normalised rise time $t_{r} / T_{m}$ for non-exceedance levels between $95 \%$ and $99.8 \%$. 

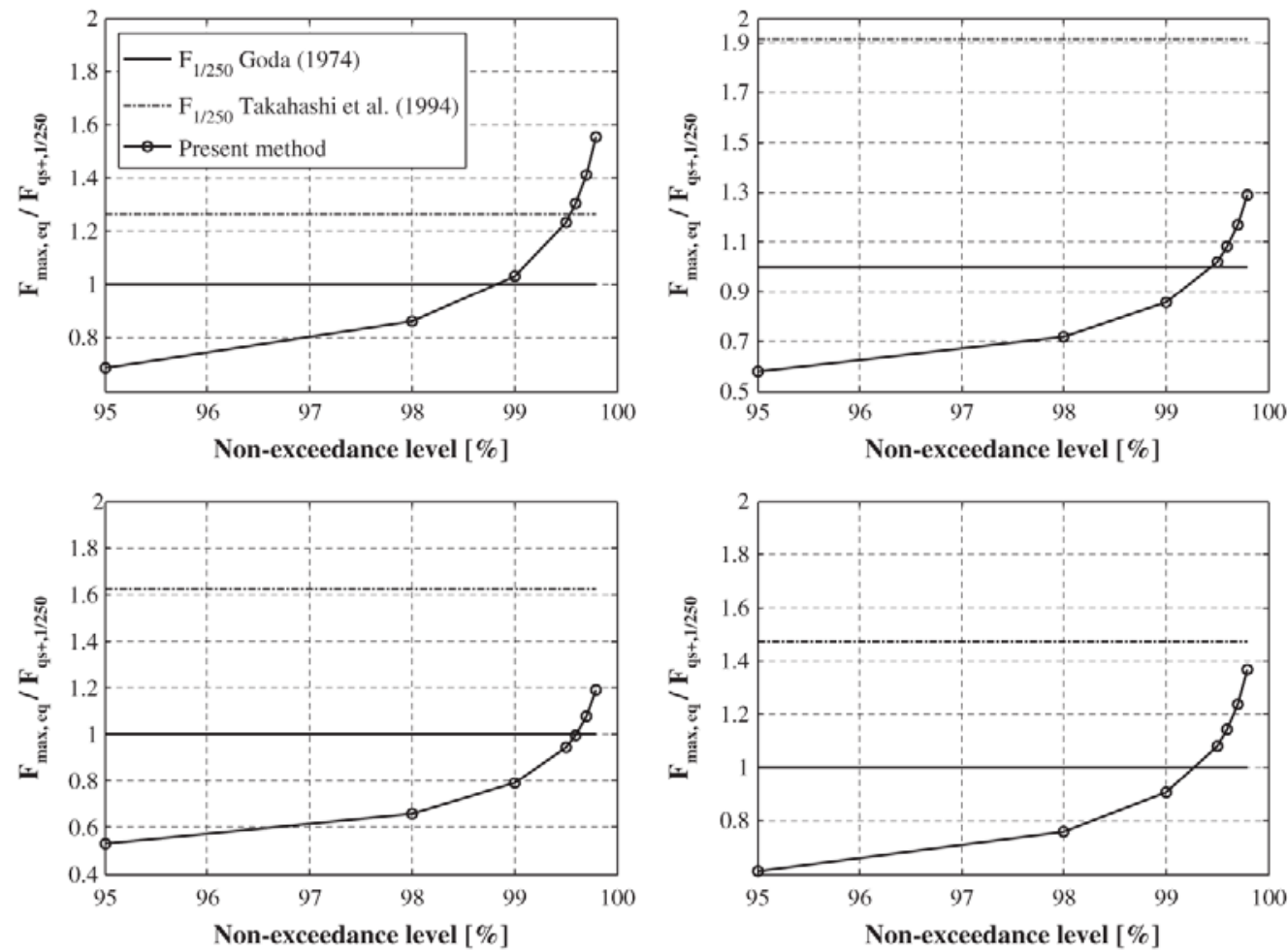

Figuire $15 \quad$ Normalised static-equivalent design load $\mathrm{F}_{\text {eq }} / \mathrm{F}_{\text {Goda }}(-0-)$ corresponding to example breakwaters in Figure 9 for increasing non-exceedance levels between 95\% and 99.8\%. In the plots are also represented predictions by Goda (1974), solid line and Takahashi et al. (1994), dashed line

For completeness, prediction by Goda (1974) and Takahashi et al. (1994) are also summarized in Table 8. Results, normalised assuming $F_{\mathrm{qs}+, 1 / 250}=F_{\text {Goda }}(1974)$, are also plotted in Figure 11 for the 5 non-exceedance joint probability level in Tab 4 superimposed to design load by Goda (1974) and Takahashi et al. (1994).

Finally, results are given in Table 9 in terms of safety factor (S.F.) against sliding. Note that for all prediction methods in Table 9, safety factors have been evaluated as:

$$
S . F .=\frac{\mu \cdot\left(W-F_{U}\right)}{F_{H}}
$$

where $\mu=0.6$ is the friction factor, $W$ is the effective weight of the caisson in water and the uplift force $F_{U}$ has been evaluated according to the classical formulation by Goda (1974).

Table 9. $\quad$ Safety factor against sliding

\begin{tabular}{ccccc}
\hline Breakwater & $\begin{array}{c}\text { Sliding } \\
{[\mathbf{m}]}\end{array}$ & $\begin{array}{c}\text { Goda } \\
\text { S.F. }\end{array}$ & $\begin{array}{c}\text { Takahashi } \\
\text { S.F. }\end{array}$ & $\begin{array}{c}\text { Present } \\
\text { method } \\
\text { S.F. }\end{array}$ \\
\hline & & $\mathbf{F}_{\mathbf{1 / 2 5 0}}$ & $\mathbf{F}_{\mathbf{1} / \mathbf{2 5 0}}$ & $\mathbf{9 9 . 6} \mathbf{\%}$ \\
Hachinohe & 1.4 & 1.14 & 0.91 & 0.87 \\
Kobe & 0.05 & 0.87 & 0.45 & 0.80 \\
Onahama & 0 & 1.14 & 0.70 & 1.14 \\
Yokohama & 0 & 1.17 & 0.79 & 1.02 \\
\hline
\end{tabular}


Observing Table 9, the following conclusion can be derived:

- In the case of Hachinobe Port breakweater, Goda's method predicts no-sliding while substantial sliding of the caisson was measured at the site. Sliding is predicted by both Takahashi et al. (1994) and the present method;

- In the case of Kobe Port breakweater, little sliding was measured and a S.F. slightly less than 1 should be expected. This is in agreement with prediction by Goda and the present method, while prediction by Takahashi et al. (1994) seems too pessimistic;

- In the cases of Onahama Port and Yokohama Port breakwaters, no-sliding was measured. This agrees with prediction by Goda and the present method, while safety factors evaluated using predictions by Takahashi et al. (1994) are too conservative;

- Prediction by the present method at $99.6 \%$ non-exceedance level compare well with both field observations and predictions by most established methods and is therefore suggested for an initial estimate of the design load.

Although values in Tables 8 and 9 are in good agreement with predictions by Goda-Takahashi's methods, the present formulation might diverge significantly from estimates using such methods under more severe conditions. As an example, estimates of design load by the present method for the cases of: Todohokke, Hacinohe $\left(8^{\text {th }}\right.$ section), Kurihama and Kaizuka port breakwaters are compared with prediction by GodaTakahashi's methods in Table 10, and in Table 11 in terms of safety factor against sliding, together with the measured sliding distance (Goda, 1973). It should be noted that values of safety factors in Tables 9 and 11 differ slightly from those published in Goda (1974), this might be due to rounding during calculations but doesn't affect the validity nor the results of the analysis since $F_{\mathrm{qs}+, 1 / 250}=F_{\mathrm{Goda}}(1974)$.

Table 10. Horizontal (shoreward) design load

\begin{tabular}{cccc}
\hline Breakwater & $\begin{array}{c}\text { Goda } \\
{[\mathbf{k N}]}\end{array}$ & $\begin{array}{c}\text { Takahashi } \\
{[\mathbf{k N}]}\end{array}$ & $\begin{array}{c}\text { Present } \\
\text { method } \\
{[\mathbf{k N ]}}\end{array}$ \\
\hline & $\mathbf{F}_{\mathbf{1} / \mathbf{2 5 0}}$ & $\mathbf{F}_{\mathbf{1 / 2 5 0}}$ & $\mathbf{9 9 . 6} \%$ \\
Todohokke & 646 & 655 & 868 \\
Hacinohe & 507 & 633 & 913 \\
Kurihama & 339 & 339 & 437 \\
Kaizuka & 202 & 268 & 424 \\
\hline
\end{tabular}

Table 11. Safety factor against sliding

\begin{tabular}{ccccc}
\hline Breakwater & $\begin{array}{c}\text { Sliding } \\
{[\mathbf{m}]}\end{array}$ & $\begin{array}{c}\text { Goda } \\
\text { S.F. }\end{array}$ & $\begin{array}{c}\text { Takahashi } \\
\text { S.F. }\end{array}$ & $\begin{array}{c}\text { Present } \\
\text { method } \\
\text { S.F. }\end{array}$ \\
\hline & & $\mathbf{F}_{\mathbf{1} / 250}$ & $\mathbf{F}_{\mathbf{1} 250}$ & $\mathbf{9 9 . 6} \%$ \\
Todohokke & 1.5 & 0.65 & 0.64 & 0.48 \\
Hacinohe & 3.7 & 0.61 & 0.49 & 0.34 \\
Kurihama & 5 & 0.88 & 0.88 & 0.68 \\
Kaizuka & 8 & 0.67 & 0.51 & 0.32 \\
\hline
\end{tabular}




\section{Conclusions, recommendations and further work}

A method has been presented that is suitable for the evaluation of the static equivalent horizontal (shoreward) load for use in performance design of caisson breakwaters subject to wave impacts.

Correlation curves between impact force and duration have been derived at fixed non-exceedance probability levels based on the analysis of the joint probability of impact maxima and rise times recorded during large scale physical model tests at CIEM / LIM wave flume of the Universitat Politècnica de Catalunya, Spain.

Use of measurements from physical model tests requires scaling up from model to prototype, in this work, impact forces from physical model tests have been scaled to prototype scale by means of an adaptation of original work by Bagnold (1939) and Takahashi et al. (1985), as explained in Cuomo et al. (2010).

Based on the analogy of caisson breakwaters with a SDOF system, it has been possible to derive simple estimates of the dynamic amplification factor for caisson breakwater subject to wave impacts. This can be used to:

- identify the worst combination of impact maxima and rise time to use in the design;

- evaluate the static-equivalent design load at different non-exceedance probability levels.

These models have been integrated within a coherent methodology for the estimation of the equivalent design wave-impact load for use in early feasibility study. The methodology accounts for the stochastic nature of the loading, the dynamic response of the structures and is corrected for scaling effects. It has been found to compare satisfactorily well with most established prediction models as well as to field measurements of sliding.

It is worth noticing that the methodology proposed in this work is relatively general and can be adapted to suit different kind of loading and structures, once the joint probability distribution of impact maxima and risetimes is known, together with the dynamic behaviour of the structure.

Unfortunately, the application of the above procedure is not as straightforward as that of previous methods (Goda, 2000 and Takahashi et al, 1994). This is mainly due to the fact that in this case the designer is asked to:

1. choose the level of non-exceedance probability to be used in the design;

2. evaluate the dynamic characteristics of the structure for use in the analysis;

3. correct peak loads for scale effect;

As far as the first point is concerned, the adoption of a particular non-exceedance level rather than "standard" values like $1 / 250,98 \%$ or similar, can only be assessed by means of a cost / benefit analysis, which can now be based on a much more effective characterization of the joint probability of wave impact maxima and rise time.

Scale effect can be accounted for by adapting the Bagnold-Mitsuyasu scaling law, as explained in Takahashi et al. (1985) and Cuomo et al. (2010).

Finally, it must be stressed that assuming the caisson breakwater to behave as a SDOF system is indeed a strong simplification and more appropriate model should be developed to reduce simplification and improve 
description of dynamics of superstructure, especially when non-linearity are expected to occur. This is always the case when sliding occurs between the superstructure and the soil foundation.

A non-linear model for the evaluation of the sliding distance of caisson breakwaters for use in performancebased design of such structures has been presented in Cuomo et al. (2010).

\section{Acknowledgements}

The authors are grateful for the precious comments received from the reviewers and particularly from Prof. Yoshimi Goda. Support from HR Wallingford, Hydraulics Applied Research and Engineering Consulting (HAREC) and the Marie Curie programme of the EU (HPMI-CT-1999-00063) are gratefully acknowledged. The authors wish to thank Dr. Shigeo Takahashi and Kenihiro Shimosako (Port and Airport Research Institute) for their precious guidance and suggestions. The Big-VOWS team of Tom Bruce, Jon Pearson, and Nicolas Napp, supported by the UK EPSRC (GR/M42312) and Xavier Gironella and Javier Pineda (LIM UPC Barcelona) supported by EC programme of Transnational Access to Major Research Infrastructure, Contract no: HPRI-CT-1999-00066, are thanked for their precious help during the physical model tests. Prof. Salvatore Grimaldi (University of Viterbo), John Alderson and Jim Clarke (HR Wallingford) are also warmly acknowledged for the many interesting discussions.

\section{References}

Athanassoulis G.A., Skarsoulis E.K., Belibassakis K.A. (1994), "Bivariate distributions with given marginals with an application to wave climate description", App. Oc. Res., vol. 16, pp. 1-17

Allsop, N.W.H. (2000) "Wave forces on vertical and composite walls" in "Handbook of Coastal Engineering", Edited by J. Herbich. New York: McGraw-Hill, 4.1-4.47

Allsop, N.W.H., McKenna, J.E., Vicinanza, D and Whittaker, T.T.J. (1996) "New design methods for wave impact loadings on vertical breakwaters and seawalls" Proc. of $25^{\text {th }}$ Int. Conf. Coastal Eng., Orlando, Florida, USA. ASCE, 2508-2521.

Allsop, N. W. H., Vicinanza, D. and McKenna, J. E. (1996) "Wave forces on vertical and composite breakwaters." Strategic Report SR 443, HR Wallingford, Oxon, UK.

Allsop N.W.H., Kortenhaus A., Oumeraci H., McConnell K. (1999) "New design methods for wave loading on vertical breakwaters under pulsating and impact conditions", Proc. of Coastal Structures '99, Santander, Spain. pp 595602

Bagnold R.A., "Interim report on wave pressure research", J. Inst. Civil Eng., 1939.

Blackmore, P. A. and Hewson, P. J. (1984) "Experiments on full-scale wave impact pressures" Coastal Eng. 8:331-346.

Box, M.J. (1965). "A new method of constrained optimization and a comparison with other methods", Computer Journal, vol. 8 (1), pp. 42-52.

Braun, H. (1980), "A simple method for testing goodness of fit in the presence of nuisance parameters", J. Royal Statis. Society, Series B (Methodological), vol. 42, $n^{\circ} 1$, pp. 53-63

Bullock, G. N., Crawford, A. R., Hewson, P. J., Walkden, M. J. A. and Bird. P.A.D. (2001) "The in ${ }^{\circ}$ uence of air and scale on wave impact pressures" Coast. Eng. 42:291-312. 
Chopra A.K. (2001) "Dynamics of structures", Upper Saddle River, NJ, USA, Prentice Hall.

Coles S., (2001). "An introduction to statistical modeling to extreme values", ed. Springer-Verlag, Ldn

Cuomo G. (2005) "Dynamics of wave-induced loads and their effects on coastal structures" PhD Thesis, University of Rome TRE.

Cuomo (2007) "Wave impacts on vertical sea walls \& caisson breakwaters", On Course International Navigation Association AIPCN-PIANC, N. 127, p. 25-38

Cuomo G., Allsop N.W.H. and McConnell K. (2003) "Dynamic wave loads on coastal structures: analysis of impulsive and pulsating wave loads" Proc. of Coastal Structures 2003, Portland, pp 356-368

Cuomo G., Lupoi G., Shimosako K. and Takahashi, S. (2007) "Dynamic response and sliding distance of composite breakwaters under breaking and non-breaking wave attack" Coastal Engineering (in review).

Cuomo G., Allsop N.W.H., Bruce T.B. and Pearson, J. (2010) "Impulsive wave loads at vertical sea walls and breakwaters" Coastal Engineering, Volume 57, Issue 4, April 2010, p 424-439.

de Groot M. B., Andersen K.H., Burcharth H. F., Ibsen L.B., Kortenhaus A., Lundgren H., Magda W., Oumeraci H. and Richwien W. (1996) "Foundation design of caisson breakwaters", publ. Nr. 198 Norwegian Geotechnical Institute, Oslo, Norway.

de Waal D.J. and van Gelder P.H.A.J.M., (2005), "Modelling of extreme wave heights and periods through copulas", Extremes, vol 8, pp. 345-356.

Evans, M., Hastings, N. and Peacock, B., (2000). Statistical Distributions, 3rd. ed., John Wiley and Sons.

Franco, L. (1994) "Vertical breakwaters: the Italian experience", special issue on vertical breakwaters, Coastal Engineering, Volume 22, Issues 1-2, January 1994, Pages 31-55

Fréchet M. (1951), "Sur lex tableaux de corrélation dont les marges sont donées", Ann. Univ. Lyon, Sect. A, Ser.3, vol. 14, pp.53-77

Fréchet M. (1956), "Sur lex tableaux de corrélation dont les marges sont donées", Comptes Rendus Acad. Sci. Paris, vol. 242, pp.24-26

Fréchet M. (1958), "Remarques au sujet la note precedent: Distributions a plusieurs variables dont les marges sont donées", by E.J. Gumbel, Comptes Rendus Acad. Sci. Paris, vol. 246, pp.2719-2720

Genest C. and Mc Kay J., (1986), "The joy of copulas: bivariate distributions with uniform marginals", The American Statistician, vol. 40, $\mathrm{n}^{\circ}$ 4, pp. 280-283

Goda Y. (1973) "A new method of wave pressure calculation for the design of composite breakwaters" Rept. Port and Harbour Res. Inst., Vol. 12., No. 3, 31-69 (in Japanese)

Goda Y. (1974) "New wave pressure formulae for composite breakwater" Proc. of $14^{\text {th }}$ Int. Conf. Coastal Eng., Copenhagen, Denmark. ASCE New York, 1702-1720.

Goda Y. (1994) "Dynamic response of up-right breakwater to impulsive force of breaking waves" Special issue on vertical breakwaters, Coastal Engineering, Volume 22, Issues 1-2, January 1994, Pages 135-158

Goda, Y. (2000) "Random seas and design of maritime structures", 443 pp, Advanced series on ocean engineering - vol. 15, World Scientific.

Gill, P.E. and Murray, W., (1975). Numerical methods for constrained optimization, Academic Press, 284 pp. 
Greenwood J.A., Landwehr J.M., Matalas N.C., Wallis J.R. (1979), "Probability weighted moments: definitions and relation to parameters of several distributions expressible in inverse forms", Water Resources Research, vol. 15, pp. 1049-1054

Hattori, M. (1994) "Wave impact pressures on vertical walls and the resulting wall deflections" Proc. of Int. Workshop of on Wave Barriers in Deep Waters. Port and Harbour Research Institute, Yokosuka, Japan, 308331.

Hattori, M. and Arami, A. (1992) "Impact breaking wave pressures on vertical walls" Proc. of $23^{\text {rd }}$ Int. Conf. Coastal Eng. ASCE, New York, 1785-1798.

Hattori, M., Arami A. and Yui T. (1994) "Impact wave pressure on vertical walls under breaking waves of various types" Special issue on vertical breakwaters, Coastal Engineering, Volume 22, Issues 1-2, January 1994, Pages 79-114

Hoskins J.R.M., Wallis J.R., Wood E.F., (1985), "Estimation of the generalized Extreme-value distribution by the method of probability-weighted moments", Technometrics, vol. 27, n³, pp.251-261

Hoskins J.R.M., (1990), "L-moments: analysis and estimation of distribution using linear combinations of order statistics", J. Royal Stat. Soc., Series B, vol. 52, pp.105-124

Jenkinson A.F., (1955), "The frequency distribution of the annual maximum (or minimum) values of meteorological elements", Quarterly Journal of the Royal Meteorological Scoiety, vol. 87, pp. 158-171.

Joe H., (1997), "Multivariate models and dependence concept", ed. Chapman \& Hall.

Johnson, N., Kotz, S. and Balakrishnan, N., (1994), "Continuous Univariate Distributions", vol. II, 2nd. ed., John Wiley and Sons.

Johnson, M.E., (1987), Multivariate statistical simulation, ed., John Wiley and Sons.

Kamel A. M. (1970) "Shock pressure on coastal structures" J. of Waterways and Harbors Division, ASCE 96, 689-699.

Karman, von T. (1929) "The impact of a seaplane floats during landing" Technical Report TN 321, National Advisory Committee for Aeronautics, Washington, USA.

Kimeldorf G. and Sampson A., (1975) "Uniform representations of bivariate distributions", Commun. in Statistics, vol. 4, pp. 617-627

Kimeldorf G. and Sampson A., (1975) "One parameter families of bivariate distributions with fixed marginals", Commun. in Statistics, vol. 4, pp. 293-301

Kirkgöz M.S. (1991) "Impact of breaking waves on vertical and sloping walls" Ocean Eng. 18, 45-59.

Kirkgöz M.S. (1992) "Influence of water depth on the breaking wave impact on vertical and sloping walls" Coastal Eng. 18, 297-314.

Kirkgöz M.S. (1995) "Breaking wave impact on vertical and sloping structures" Ocean Eng. 22:35-48.

Klammer P., Oumeraci H. and Partenscky H.W. (1994) "Oscillatory motions and permanent displacement of caisson breakwater subject to impulsive breaking wave loads." Proc. of $24^{\text {th }}$ Int. Conf. Coastal Eng., Kobe, Japan. ASCE, 1255-1268. 
Klammer P., Kortenhaus A. and Oumeraci H. (1996) "Wave impact loading of vertical face structures for dynamic stability analysis - prediction formulae" Proc. of $25^{\text {th }}$ Int. Conf. Coastal Eng., Orlando, Florida, USA, ASCE New York, No. 25, Volume 2, Chapter 196, pp. 2534-2547

Kortenhaus A. and Oumeraci H. (1998) "Classification of wave loading on monolithic coastal structures." Proc. of $26^{\text {th }}$ Int. Conf. Coastal Eng., Copenhagen, Denmark. ASCE, New York, 867-880.

Lamberti A. and Martinelli L. (1998) "Prototype measurements of the dynamic response of caisson breakwaters" Proc. of $26^{\text {th }}$ Int. Conf. Coastal Eng., Copenhagen, Denmark. ASCE New York,pp. 1972-1985 Lawless J.F. (1980) Statistical models and methods for lifetime data, John Wiley, pp. 580.

Lundgren H. (1969) "Wave shock forces: an analysis of deformations and forces in the wave and in the foundation" Proceedings of Symposium on Research on wave action". Delft Hydraulics Lab. Delft, the Netherlands, Paper 4.

Lysmer, J. and Richart, F. E. (1966) "Dynamic response of footings to vertical loading" J. of Soil Mech. and Foundations Division, ASCE 92 No. SM1:65-91.

McConnell, K. and Kortenhaus, A. (1996). "Analysis of pressure measurements from hydraulic model tests and prototype measurements." Proc. Task 1 Belfast Workshop, PROVERBS Project, Leichtweiss Institut, Technical University of Braunschweig, Braunschweig, Germany. MAST III/PROVERBS.

Ming G., Guanying D., Jihua Y. (1988) "Dynamic studies on caisson-type breakwaters" Proc. of Int. Conf. Coastal Eng., Torremolinos, Spain, ASCE, pp. 2469-2478.

Mitsuyasu H. (1966) "Shock pressure of breaking waves" Proc. of $10^{\text {th }}$ Int. Conf. Coastal Eng., Tokyo, Japan. ASCE New York, 268-283.

Muraki Y. (1966) "Field observations of wave pressure, wave run-up and oscillation of breakwater" Proc. of $10^{\text {th }}$ Int. Conf. Coastal Eng., Tokyo, Japan. ASCE, pp. 302-321

Nelder J.A. and Mead R. (1965) "A simplex method for function minimization", Computer Journal, vol. 7 (4), pp. 308-313

Nelsen R.B., (2006). "An introduction to copulas", $2^{\text {nd }}$ ed. Springer-Verlag, NY

Ochi M.K., (1990). "Applied probability and stochastic process in engineering and physical sciences", Ed. John Wiley, pp. 500

Ochi M.K., (1998). "Ocean waves. The stochastic approach", Ed. Cambridge University Press, pp. 319

Oumeraci, H., Partenscky, H.W., Kohlhase, S. and Klammer, P. (1992) "Impact loading and dynamic response of caisson breakwaters - Results of large-scale model tests" Proc. of $23^{\text {rd }}$ Int. Conf. Coastal Eng., Venice, Italy. ASCE, New York, 1475-1488.

Oumeraci, H. (1994) "Review and analysis of vertical breakwater failures - lessons learned", Special issue on vertical breakwaters, Coastal Engineering, Volume 22, Issues 1-2, January 1994, Pages 3-29

Oumeraci H., Klammer P. and Partenscky H.W. (1993) "Classification of breaking wave loads on vertical structures" J. of Waterways, Port, Coastal and Oc. Eng. Vol. 119, No. 4, July/August 1993, pp. 381-397

Oumeraci H. and Kortenhaus A. (1994) "Analysis of dynamic response of caisson breakwaters" Special issue on vertical breakwaters, Coastal Engineering, Volume 22, Issues 1-2, January 1994, Pages 159 - 183 
Oumeraci H., Kortenhaus A., Allsop N.W.H., de Groot M.B., Crouch R.S., Vrijling J.K., Voortman H.G. (2001) "PRObabilistic design tools for VERtical BreakwaterS", 392 pp, Balkema, Rotterdam.

Pandely M.D., Van Gelder P.H.A.J.M., Vrijling J.K., (2001), " The estimation of extreme quantiles of wind velocity using L-moments in the peak-over-threshold approach”, Structural Safety, vol. 23, pp. 179-192

Partenscky, H.W. (1988) "Dynamic forces due to wave breaking at vertical coastal structures" Proc. of $21^{\text {st }}$ Int. Conf. Coastal Eng., Torremolinos, Spain. ASCE, New York, 2504-2518.

Pearson J., Bruce T.B., Allsop N.W.H., (2002) "Violent wave overtopping - measurements at large and small scale" Proc. of $28^{\text {th }}$ int. Conf. Coastal Eng ASCE, Cardiff, UK, pp. 2227-2238

Pedersen J. (1997) "Dynamic response of caisson breakwaters subjected to impulsive wave loading -design diagrams for static load factors" Proc. of $1^{\text {st }}$ overall project workshop, Las Palmas, Gran Canaria, vol. A 417. Mast III, 22pp.

Peregrine, D. H. (2003) "Water wave impact on walls" Ann. Rev. Fl. Mech. 35:365-374

Petruskas C. and Aagaard P.M., (1971), "Extrapolation of historical storm data for estimating design wave height", J. Petroleum Eng., vol. 11, pp.23-37

Plackett R.L., (1965), "A class of bivariate distributions", J. Ann. Statistical Assoc., vol. 60, pp. 516-522

Pickands J. III, (1975), "Statistical Inference Using Extreme Order Statistics", Annals of Statistics, vol. 3, n. 1, pp. 119-131.

Piscopia, R., (2003). "On the Optimal Fitting of a Ten-Parameter Model to Observed Wave Spectra", ISOPE 13th conf., vol. III, pp. 234-240.

Piscopia, R., Panizzo A., De Girolamo P., Franco L. (2002). "Study on the scale effects in mobile gates physical test - Wave spectrum parameterization out of the Venice Lagoon's mouths", Magistrato alle Acque di Venezia, conv. rep.7725-23.12.97., (in Italian), pp. 87.

Piscopia, R., Cuomo G. and Allsop N.W.H. (2007) "Evaluation of design impact loads based on joint probability of impact maxima and rise times", Proc. Of Coastal Structures Conf., Venice, Italy, World Scientific, Singapore, Vol. I, pp. 883-894.

Richert G. (1968) "Experimental investigation of shock pressures against breakwaters" Proc. of $11^{\text {th }}$ Int. Conf. Coastal Eng., London, UK. ASCE New York, 954-973.

Schmidt R., Oumeraci H. and Partenscky H.W. (1992) "Impact loading induced by plunging breakers on vertical structures" Proc. of $23^{\text {rd }}$ Int. Conf. Coastal Eng., Venice, Italy, ASCE New York, pp. 1545-1558

Sklar A., (1959), "Fonctions de repartition a n dimensions et leurs marges", Publ. Inst. Stat. Univ. Paris, vol. 8, pp. 229-231

Spendley W., Hext G.R. and Himsworth F.R. (1962) "Sequential application of simplex designs in optimization and evolutionary design", Technometrics, vol. 4, pp. 441-461

Takahashi S., Tanimoto K. and Miyanaga S. (1985) "Uplift wave forces due to compression of enclosed air layer and their similitude low" Coast. Eng. In Japan, Vol. 28, 191-206.

Takahashi, S., Tanimoto, K. and Shimosako, K. (1994) "A proposal of impulsive pressure coefficient for the design of composite breakwaters" Proc. Hydro-Port'94, vol. 1. Port and Harbour Research Institute,

Yokosuka, 489-504. 
Walkden M. J. A., Hewson P. J., and Bullock G. N. (1996) "Wave impulse prediction for caisson design" Proc. of $25^{\text {th }}$ Int. Conf. Coastal Eng., Orlando, Florida, USA, ASCE New York, 2584-2597.

Walkden, M.J.A. and Bruce, T.B. (1999) "Scatter in wave impulse maxima: A review", Proc. of Coastal Structures '99, Vol. I, 439-446.

Weggel J.R. and Maxwell W.H. (1970) "Numerical model for wave pressure distributions" J. of the Waterways, Harbor and Coastal Eng. Division, ASCE, August, no.ww3, pp. 623-642

Witte H.H. (1990) "Wave impact loading on a vertical wall with respect to structure response" Report for the Federal Waterways and Research Institute - Coastal Department, 30 pp.

Wolf J.P. (1988) "Soil-structure-interaction analysis in time domain", Prentice Hall, 416p 
Notation
$A, B, k$
[-] position, scale and shape parameter of the GEV distribution

\section{$\hat{A}, \hat{B}, \hat{k}$}

$A_{V}$

$a$ and $b$

$a_{1,2}, b_{1,2}$

$\mathrm{c}_{1,2}, \mathrm{~d}_{1,2}$

$C(F(x), G(y))$

$C_{P}(G(y) \mid P(x)=\zeta)$

$C_{G}(P(x) \mid G(y)=\xi)$

$c(P(x), G(y))$

$c_{d}$

$D$

$d$

$d_{\text {eff }}$

$F(x, y)$

$F_{P}(y \mid x)$

$F_{h}$

$F_{\text {imp }}$

$F_{\text {imp }}$ *

$F_{\text {max }}$

$F_{\text {min }}$

$F_{\text {qs+ }}$

$F_{q S+, 1 / 250}$

$g$

$H_{b}$

$H_{\text {mo }}$

K

$k_{m}$

I
[-] estimations of the position, scale and shape parameter of the GEV distribution

$\left[\mathrm{m}^{3}\right]$ volume of air expelled at impact

[-] empirical coefficients

[-] fitting parameters

[-] fitting parameters

[-] copula bivariate cumulative probability function

[-] copula bivariate conditional probability function

[-] copula bivariate conditional probability function

[-] copula bivariate density probability function

[-] empirical parameter

$[\mathrm{kNs} / \mathrm{m}]$ damping

$[\mathrm{m}]$ water depths during tests

[m] effective water depth at the structure

[-] bivariate cumulative probability distributions

[-] conditional probability distribution function

[N] horizontal force

$[\mathrm{N}]$ impact force

[-] relative maximum impact force

[N] maximum landward impact force

[N] background noise-threshold level

[N] maximum quasi-static load

$[\mathrm{N}]$ average of the 4 higher quasi-static force values within a 1000 waves test

$\left[\mathrm{m} \mathrm{s}^{-2}\right]$ gravitational acceleration

[m] wave height at breaking

[m] significant spectral wave height

$[\mathrm{kN} / \mathrm{m}]$ stiffness

[-] mass parameter

[Pa s] pressure impulse 


\begin{tabular}{|c|c|}
\hline$i$ & [-] sample ranking index \\
\hline M & {$[\mathrm{kg}]$ mass } \\
\hline$M_{h}$ & {$[\mathrm{Nm}]$ total overturning moment } \\
\hline$N$ & [-] sample size \\
\hline$N_{z}$ & [-] number of waves \\
\hline$P(x), G(y)$ & [-] univariate cumulative probability distributions \\
\hline$P_{i, N}$ & [-] non-exceedance cumulate sample frequency \\
\hline$P^{k}$ & {$[\mathrm{~Pa}]$ pressure recorded by the $k^{\text {th }}$ pressure transducer } \\
\hline$P_{\max }$ & [Pa] maximum impact pressure \\
\hline$R_{c}$ & {$[\mathrm{~m}]$ structure freeboard } \\
\hline$T_{m}$ & [s] mean wave period \\
\hline$T_{0}$ & [s] natural period of oscillation the structure \\
\hline$T_{0, n}$ & [s] natural period of oscillation the un-damped structure \\
\hline$T_{0, D}$ & [s] natural period of oscillation the damped structure \\
\hline$t$ & [s] time needed to transfer wave kinetic energy to the wall \\
\hline$t_{0}$ & [m] time corresponding to the beginning of wave impact \\
\hline$t_{r}$ & [s] impact rise-time \\
\hline$t_{r}^{*}$ & {$[-]$ relative rise-time } \\
\hline$t_{d}$ & {$[\mathrm{~s}]$ impact duration } \\
\hline$U$ & {$\left[\mathrm{~ms}^{-1}\right]$ breaker velocity } \\
\hline$z^{k}$ & [m] absolute position of the $k^{\text {th }}$ transducer up the wall \\
\hline$\beta_{r}, r=0,1,2$ & [-] probability weighted moments \\
\hline$\hat{\beta}_{r}, r=0,1,2$ & [-] probability weighted moment estimations \\
\hline$\Delta \mathrm{z}$ & {$[\mathrm{m}]$ distance up the wall between two successive transducers } \\
\hline$\rho$ & {$\left[\mathrm{kg} \mathrm{m}^{-3}\right]$ water density } \\
\hline$\mu, \eta, \kappa$ & [-] position, scale and shape parameters of the GP distribution \\
\hline$\hat{\mu}, \hat{\eta}, \hat{\kappa}$ & [-] estimations of position, scale and shape parameter of the GP distribution \\
\hline$\psi$ & [-] dependence coefficient \\
\hline$\hat{\psi}$ & [-] dependence coefficient estimation \\
\hline$\lambda_{\mathrm{s}}$ & [-] scaling factor \\
\hline
\end{tabular}


$\vartheta$

$\Lambda$

$\Omega$
[-] assigned rise-time value

[-] numerical constant

[-] assigned probability level 


\section{APPENDIX - The "Complex" fitting method}

The Complex Method (CM) is a general, multivariable, direct-search, optimization technique widely applied to nonlinear problems with inequality constraints (Box, 1965) whose application becomes particularly convenient whenever derivatives of the objective function (i.e. function to be minimized) are difficult to obtain. The method represent a further development of the Simplex Method (SM), which is a unconstrained direct-search optimization method (Spendley et al., 1962). The development introduced by Box involves the opportunity to bound the search for the optimal values of parameter set into a fixed region of the variables space.

The CM is easily implementable and is efficient in obtaining the global optimum while imposing inequality constraints on explicit and implicit variables. Widely used in chemical engineering, the CM has only rarely been applied in coastal engineering (Piscopia, 2003) and is briefly described in the following.

The CM is based on the adjustment of a geometric figure, called "complex", having $2 k+1$ vertices in the $k$-dimensional parameter-space, being $k$ the number of variables in the objective function $\Phi(\mathbf{x})$. The initial complex shape, given by the distribution of its vertexes into the parameter-space, is completely arbitrary. Namely, $2 k+1$ points are randomly selected and the minimizing function is there evaluated. The vertexes are then ranked as a function of their level (i.e. the value of the objective function in the vertex). The resulting function values define, step by step, the marching direction of the solution on the basis of simple rules. The basic one is to replace the "worst" vertex in the figure, (defined as the vertex with the highest function values, also termed level) by mirroring it with respect to the centroid of the other vertexes. This process allows the "complex" to move within the variable space toward more favourable (with decreasing level) parameter settings. The process is repeated until all the vertexes collapse onto the centroid or until a convergence criterion is met.

The definitions of the centroid $(\chi)$ of all vertices $\left(\mathbf{x}_{i}\right)$ other than the worst $\left(\mathbf{x}_{j}\right)$ and of the new reflected trial $\left(\mathbf{x}_{j}^{\text {new }}\right)$ are respectively

$$
\begin{aligned}
& \chi=\frac{1}{n} \sum_{j \neq i=1}^{n+q} \mathbf{x}_{i} \\
& \mathbf{x}_{j}^{n e w}=\left(1+\delta_{1}\right) \chi-\delta_{1} \mathbf{x}_{j}(\mathrm{~A} 2)
\end{aligned}
$$

being $\delta_{1}>1$ the reflection coefficient that controls the convergence rate.

For the complex to improve the value of the control parameters, the new trial should always return a value of the objective function value smaller than the previous $\left(\Phi\left(\mathbf{x}_{j}^{\text {new }}\right)<\Phi\left(\mathbf{x}_{j}\right)\right)$. When this is not the case, the general procedure changes: the worst vertex is kept in the complex and the vertex having the second higher level is reflected through the centroid. If this movement yields an improvement then the new trial is retained. On the contrary, if the search is moving uphill to higher levels, then the reflection rule is not further applied and the new trial is obtained by contracting the worst vertex in the complex, i.e.

$$
\mathbf{x}_{j}^{\text {new }}=\left(1-\delta_{2}\right) \chi+\delta_{2} \mathbf{x}_{j}
$$

in which $0 \leq \delta_{2} \leq 1$ is the negative contraction coefficient which controls the collapse of the vertices into the centroid. 
Other rules can be added to the aforementioned two to enhance the efficiency of the optimisation process. For instance, vertexes retained in the complex for more than a specified number of steps could be re-evaluated, allowing the complex to move away from a local minimum.

Nelder and Mead (1965) increased the convergence rate allowing the shape of the complex to be modified according to the result of the reflection so that it can expand or contract itself, enabling the routine to accelerate along a successful track of improvement or to home around the optimum (see figure A1). Expansion is attempted every time eq. (A2) provides a minimum value of the level. In this cases $\mathbf{x}_{j}$ is expanded according to

$$
\mathbf{x}_{j}^{\text {new }}=\left(1+\delta_{3}\right) \chi-\delta_{3} \mathbf{x}_{j}
$$

where $1<\delta_{1}<\delta_{3}$ is the expansion coefficient. If eq. (A4) results in an even smaller trial than that obtained using eq. (A2), the expansion outcome is retained. Otherwise the expansion trial is discharged and the worst vertex is replaced by the outcome of eq. (A2). Analogously, positive contraction is performed if the complex reaches a worst point, i.e. eq. (A2) gives a trial $\mathbf{x}_{j}^{\text {new }}$ with $\max \left[\Phi\left(\mathbf{x}_{i \neq j}\right)\right]<\Phi\left(\mathbf{x}_{j}^{n e w}\right)<\Phi\left(\mathbf{x}_{j}\right)$. In this cases $\mathbf{x}_{j}$ is contracted according to

$$
\mathbf{x}_{j}^{\text {new }}=\left(1+\delta_{4}\right) \chi-\delta_{4} \mathbf{x}_{j}
$$

in which $0 \leq \delta_{4} \leq 1$ is the positive contraction coefficient that controls the collapse onto the centroid.

The optimization procedure stops when one of the following criteria is met one of the following criteria:

$$
\begin{aligned}
& \max \left[\Phi\left(\mathbf{x}_{i}\right)\right] \leq 10^{-6} \\
& 2\left|\left\{\max \left[\Phi\left(\mathbf{x}_{i}\right)\right]-\min \left[\Phi\left(\mathbf{x}_{i}\right)\right]\right\} /\left\{\max \left[\Phi\left(\mathbf{x}_{i}\right)\right]+\min \left[\Phi\left(\mathbf{x}_{i}\right)\right]\right\}\right| \leq 10^{-6} \text { (A7) } \\
& m>10^{6}
\end{aligned}
$$

being $m$ the iteration index and $i=1,2, \ldots, 2 k+1$.

With the aim to constrain the search path within a limited parameter space, Box (1965) imposed a range $\left[I_{h}, u_{h}\right]$ on each variable, which therefore must satisfy the following constraints:

$$
\begin{aligned}
& \Gamma_{h}=x_{i, h}-l_{h} \geq 0 \\
& \Gamma_{h+k}=u_{i, h}-x_{h} \geq 0
\end{aligned}
$$

in which $-\infty \leq I_{h}<u_{h} \leq \infty, h=1,2, \ldots, k$ and $i=1,2, \ldots, 2 k+1$.

If eq. (A2) results in a trial $\mathbf{x}_{j}^{\text {new }}$ that violates one of the constrains $\Gamma_{h}$, the outrange trial is reset inside the allowable bound and the resulting point is retained as the new vertex. If eq. (A2) results in a trial $\mathbf{x}_{j}^{\text {new }}$ that violates two or more constraints $\Gamma$, then successive moves are made halfway back toward the centroid, until a feasible vertex is attained.

If no reliable guess point is available, the vertices of the initial complex can be assigned as:

$$
x_{i, h}=l_{h}+\left(u_{h}-l_{h}\right) \lambda
$$


being $\lambda$ a pseudo-random deviate uniformly distributed over $(0,1), h=1,2, \ldots, k$ and $i=1,2, \ldots$, $2 k+1$. If a suitable guess point $\left(\mathbf{x}_{0}\right)$ is available, the initial complex shape ought to be drawn starting from it. In the present work we use the following expression:

$$
x_{i, h}=x_{o, h}+\lambda\left(u_{h}-l_{h}\right) / 10
$$

A flow chart summarising the essential steps of the CM is given in Figure A2. 